\title{
Disruption of Cerebellar Maturation by an Antimitotic Agent Impairs the Ontogeny of Eyeblink Conditioning in Rats
}

\author{
John H. Freeman, Jr., ${ }^{1}$ Stan Barone, Jr., ${ }^{2}$ and Mark E. Stanton ${ }^{1,2}$ \\ 'Department of Psychology, University of North Carolina at Chapel Hill, Chapel Hill, North Carolina 27599 and \\ ${ }^{2}$ Neurotoxicology Division, National Health and Environmental Effects Research Laboratory, U.S. Environmental \\ Protection Agency, Research Triangle Park, North Carolina 27711
}

\begin{abstract}
This study represents an attempt to establish a relationship between maturation of the cerebellum and the ontogeny of eyeblink conditioning in the rat. Experiments 1 and 2 examined the effects of disrupting cerebellar maturation by neonatal exposure to the antimitotic agent methylazoxymethanol (MAM) on the ontogeny of eyeblink conditioning in infant rats. Experiment 1 demonstrated that neonatal exposure to MAM on Postnatal Day 4 (PND4) and 7 severely disrupted cerebellar maturation. This effect appeared to be specific in that there was no overt dysmorphology in other brain regions. MAM treatment also severely disrupted associative eyeblink conditioning in rats given training on PND24 and 25. However, exposure to MAM had no effect on the unconditioned response, T-maze delayed alternation, or conditioned suppression of ongoing behavior. In Experiment 2, MAM was given on PND4 and 7 and pups were tested behaviorally on PND17-18, 20-21, or 31-32. Cerebellar hypoplasia was most dramatic shortly after exposure. The cerebellar cortex continued to mature after exposure to MAM, but development of morphological endpoints examined here were static from PND19 to 33. Eyeblink conditioning was impaired at all ages, indicating that there was no functional recovery following neonatal exposure to MAM over the age range tested. These experiments suggest that normal cerebellar maturation may be important for the ontogeny of eyeblink conditioning.
\end{abstract}

[Key words: cerebellum, ontogeny, conditioning, methylazoxymethanol (MAM), antimitotic, rat]

The current study represents a continuation of our attempt to establish the eyeblink conditioning preparation as a model system for studying the relationship between neural maturation and the ontogeny of learning. One advantage of using the eyeblink

Received Feb. 15, 1995; revised June 23, 1995; accepted July 6, 1995.

Disclaimer: this manuscript has been reviewed by the Hcalth Effects Research Laboratory, U.S. Environmental Protection Agency, and approved for publication. Mention of trade names or commercial products does not constitute endorsement or recommendation for use.

We thank Steven Andrews, Christy Carter, Gregory Fox, Najwa HaykalCoates, Donna Reefe, and Ronabeth Robbins for technical assistance and Julia Davis for developing and printing the photomicrographs. We also thank Dr. Joseph Ali, Baker Bailey, Lawrence Koffa, Alan Lee, and Dr. Ronald Skelton for helping to develop and implement the eyeblink conditioning apparatus. This article is based upon a portion of a doctoral dissertation submitted by J.H.F. to the Department of Psychology, University of North Carolina at Chapel Hill, under the sponsorship of M.E.S

Correspondence should be addressed to John H. Freeman, Jr., Beckman In stitute, University of Illinois, 405 North Mathews Avenue, Urbana, IL 61801. Copyright $\bigcirc 1995$ Society for Neuroscience $0270-6474 / 95 / 157301-14 \$ 05.00 / 0$ conditioning preparation for this purpose is that the neural circuitry underlying the conditioned and unconditioned responses has been well characterized (e.g., McCormick and Thompson, 1984; Thompson, 1988). In addition, the key neural structure in this circuitry, the cerebellum, shows dramatic development during the first 3 weeks of life in rats (Altman, 1982). As a result, use of the eyeblink conditioning paradigm with developing rats could provide an excellent opportunity for studying the ontogeny of learning and its neural bases.

Behavioral characterization of the ontogeny of eyeblink conditioning began when a method for conditioning freely moving adult rats (Skelton, 1988) was adapted for use with the infant rat (Stanton et al., 1992). This study demonstrated that associative eyeblink conditioning developed between postnatal day 17 (PND17) and 24. Subsequent behavioral experiments examined the effects of conditioning parameters and demonstrated that variations in interstimulus interval or unconditioned stimulus intensity did not alter this developmental trend (Freeman et al., 1993). In the present study, we begin to explore the neural bases of the ontogeny of eyeblink conditioning, in particular the role of cerebellar maturation (Stanton et al., 1992; Freeman et al., 1993).

In the rat, the volume of the cerebellar cortex increases more than 20-fold during the first three postnatal weeks (Altman, 1969). Cells of the deep nuclei, Purkinje cells and cells within the brainstem nuclei that are sources of cerebellar afferents and efferent targets are generated before birth (Altman, 1982). In contrast, granule, stellate, and basket cells are generated after birth (Altman, 1972a-c). In addition to the massive generation of microneurons in the cerebellar cortex, each of the cell types within this structure undergo extensive morphological development during the postnatal period in the rat (Altman, 1972b; Berry and Bradley, 1976; Anderson and Flumerfelt, 1985).

The cerebellum and several of its brainstem connections are thought by some to be critical for the acquisition and expression of the eyelid CR (Thompson, 1988). Lesions of the cerebellar deep nuclei that are ipsilateral to the trained eye produce severe deficits in the expression of previously learned CRs (McCormick et al., 1982; Clark et al., 1984; Lavond et al., 1985; Yeo et al., 1985; Welsh and Harvey, 1989; Steinmetz et al., 1992). These deficits in conditioned responding may be accompanied by either a relatively minor UR deficit (Welsh and Harvey, 1989; Steinmetz et al., 1992) or by no UR deficit (McCormick et al., 1982; Clark et al., 1984; Lavond et al., 1985; Yeo et al., 1985). Studies involving electrophysiological recordings of cells within the cerebellum and/or reversible inactivation of the deep nuclei further 
suggest that the convergence of CS and US information occurs within the cerebellum and that the plasticity necessary for conditioning may be localized within this structure (McCormick and Thompson, 1984; Chapman et al., 1990; Clark et al., 1992; Krupa et al., 1993). The cerebellar cortex seems to be critical for acquisition and maintenance of normal CRs (e.g., timed with US onset and increased in amplitude with training), but it is not essential for production of responses that meet minimal criterion for CRs. Lavond et al. (1987) found that cerebellar cortical lesions in animals trained before the lesion, produced a recoverable deficit in retention of $C R$ percentage with a persistent deficit in CR amplitude. A subsequent study demonstrated that acquisition of eyelid conditioning was delayed by lesions of hemispheric lobule VI, with persistent deficits in CR amplitude (Lavond and Steinnetz, 1989). These two studies support the notion that the cerebellar cortex is important for establishing CRs by modulating the activity of the deep nuclei, but is not essential for maintenance of previously established CRs. A more recent study demonstrated that animals given extensive overtraining prior to surgery had recoverable deficits in $\mathrm{CR}$ frequency with permanent deficits in CR amplitude (Harvey et al., 1993). In summary, the rate of acquisition of eyeblink conditioning and the maintenance of $\mathrm{CR}$ amplitude depend upon the cerebellar cortex and deep nuclei, while it appears that small amplitude CRs can be established without the cortex.

This study was designed to determine whether impairing the maturation of cerebellar microneurons by early postnatal exposure to the antimitotic agent methylazoxymethanol (MAM), would disrupt the ontogeny of eyeblink conditioning in rats. Systematic studies of the effects of exposure to MAM at different postnatal ages have not been done. Studies describing the antimitotic effects of neonatal $\mathrm{x}$-irradiation exposure showed that cerehellar granule cells are generated steadily during the first 2 weeks of life and that the degree of granule cell depletion following $x$-irradiation depends upon the number of exposure days rather than the dose or the absolute number of exposures (Altman and Anderson, 1972, 1973). Considering that the pattern of effects of neonatal MAM exposure appear similar to those of X-irradiation (Chen and Hillman, 1986, 1989; Stanton and Freeman, 1994), it seemed likely that exposure to MAM during the first week of life would also cause massive cerebellar hypoplasia. In this study, we asked whether this effect would impair the ontogeny of eyeblink conditioning.

\section{Experiment 1}

The purpose of Experiment 1 was to examine the effects of early exposure to MAM on ccrcbcllar anatomy and cycblink conditioning during the weanling period (PND24-27). Because systemic administration of MAM could disrupt maturation of a number of neural systems, an attempt was made to determine whether the behavioral effects of MAM reflected its actions on the cerebellum or other developing brain systems. In order to assess the behavioral specificity of the effects of MAM, we examined the ability of treated pups to learn T-maze delayed alternation, a task that we have shown reveals effects of neonatal damage to the hippocampal system or prefrontal cortex (Freeman and Stanton, 1991, 1992). In addition, we developed a test of conditioned suppression as a putative measure of fear. It has been shown that conditioned fear states established during eyeblink conditioning do not depend on the cerebellum (Thompson et al., 1987), but rather probably involve the amygdala (Weisz and LoTurco, 1988; Weisz et al., 1992). Thus, deficits in eye- blink conditioning but not T-maze delayed alternation or conditioned suppression would suggest that the behavioral effects of MAM could be attributed to cerebellar hypoplasia or at least that the amygdala and hippocampus were functionally intact.

In Experiment 1, pups were given injections of either saline or MAM (20 mg/kg) on PND4 and 7. Pups were then trained on eyeblink conditioning on PND24 and 25, using either paired or unpaired conditioning procedures. The ages of testing were chosen because normal pups at this age show robust associative eyeblink conditioning (Stanton et al., 1992; Freeman et al., 1993). Both paired and unpaired training groups were included in order to assess whether postnatal exposure to MAM would cause a selective deficit in associative learning. Animals were tested on six 100-trial sessions in order to help assess whether conditioning deficits in MAM-treated pups would recover following extensive training. Different subsets of these animals were assigned to the other behavioral tests. The neuroanatomical effects of MAM were examined by qualitative and quantitative analysis of Nissl-stained sections in the sagittal plane. The entire brain was surveyed with particular attention directed towards the cerebellum and its efferent and afferent brainstem nuclei.

\section{Materials and Methods}

Subjects. Sixty-six Long-Evans rat pups (32 saline; 34 MAM, from 14 litters) served as subjects in eyeblink conditioning. Of these, a subset was subsequently trained on T-maze delayed alternation (Saline, $n=$ 11; MAM, $n=10$ ) and another subset on conditioned suppression (Saline/Paired, $n=8$; MAM/Paired, $n=8$; Saline/Unpaired, $n=4$; MAM/Unpaired, $n=4$ ). The rats were offspring of time-bred primiparous females obtained from Charles River (Raleigh, NC) on either the second or fourteenth day of gestation. Offspring were raised in the animal colony at the U.S. Environmental Protection Agency, Research Triangle Park, NC. This facility is certified by the American Association for Accreditation of Laboratory Animal Care. All subjects were maintained on a $12 \mathrm{hr}$ light, $12 \mathrm{hr}$ dark photoperiod, with light onset at 7:00 A.M. The pups were born and housed with their mothers on a bed of wood shavings in plastic cages measuring $48 \times 27 \times 20 \mathrm{~cm}$. All litters were culled to four males and four females by the third day after birth. Age of the pups was determined by checking for births during the light phase of the light-dark cycle and designating that day as postnatal day 0 (PND0). Subjects remained undisturbed with their mothers except for periodic cage cleaning and experimental manipulations (e.g.. dosing, eyeblink conditioning surgery, and testing). Pups were weaned on PND21. They were removed from their dams and housed with samesex littermates. Littermates were assigned to different experimental groups (sec below) in all experiments with the restriction that no more than one female and one male from each litter was assigned to a given group.

Methylazoxymethanol (MAM) dosing. On PND4 and 7, pups were taken momentarily from the home nest, individually identified with paw tattoos, and injected (s.c.) with physiological saline or with $20 \mathrm{mg} / \mathrm{kg}$ methylazoxymethanol (Sigma Chemical Company, St. Louis, MO) dissolved in saline. Doses of MAM were administered in a volume of 10 $\mu \mathrm{l} / \mathrm{gm}$ body weight. Pilot experiments showed that pups suffered from severe liver damage if given more than two injections of MAM at either 10 or $20 \mathrm{mg} / \mathrm{kg}$ during the first two postnatal weeks or if they were given even a single injection after PND10. Two exposures of $10 \mathrm{mg} /$ $\mathrm{kg}$ had a negligible effect on cerebellar maturation. However, pups could survive two injections of $20 \mathrm{mg} / \mathrm{kg}$ as neonates and these animals showed significant cercbellar hypoplasia. This served as the basis for the MAM exposure in the present experiment. When two same-sex littermates received the same dosing treatment, they were assigned to different behavioral groups.

Eyeblink surgery. The surgical procedure has been described previously (Stanton et al., 1992; Freeman et al., 1993). On the day prior to training (PND23), pups were removed from their home cage and anesthetized by exposure to Metofane (methoxyfluorane, Pitman-Moore, Mundelein, IL) vapor in a closed container for 4-5 min. Upon the onset of anesthesia, pups were fitted with head stages as follows: differential EMG electrodes were subcutaneously implanted in the upper eyelid 
muscles and a ground electrode was placed subcutaneously at the back of the neck. Bipolar stimulating electrodes (for delivering the US) were implanted subdermally immediately dorsal-caudal to the left eye. Electrode leads terminated in Amphenol pins that were secured to the skull with dental acrylic according to a procedure developed for infant rats by Gilbert and Cain (1980). The head stage was connected to a commutator, allowing the animal to move frecly during testing. Following surgery, pups were placed individually in mouse tubs and given ad lib food and water.

Eyeblink conditioning apparatus. We used a modified version of the apparatus used in our previous reports (Stanton et al., 1992; Freeman et al., 1993). The conditioning apparatus used in these experiments consisted of four small animal chambers (BRS/LVE, Laurel, MD), each lined with $5 \mathrm{~cm}$ thick sound absorbing foam (Illbruck, Minneapolis, $\mathrm{MN})$. Within each animal chamber was a $22 \times 22 \times 26 \mathrm{~cm}$ stainless steel mesh cage $(1 \mathrm{~cm}$ grid) where the animal was kept during conditioning. Each chamber had a dim house light and an exhaust fan that were both left running while animals were being tested. Background noise from the fan was approximately $70 \mathrm{~dB}$. One wall of the chamber was fitted with two horns that could independently produce tones of up to $100 \mathrm{~dB}$ SPL, with a frequency range of approximately 1000-12,000 Hz (model number 40-1379, Radio Shack, Fort Worth, TX). Each chamber was fitted with a commutator that carried electrode leads to a head stage designed for freely moving rat pups. The electrode leads were connected via the commutators (model number CAY-675-12, Airflyte, Bayonne, NJ) to peripheral equipment and two IBM compatible computers (two test chambers per computer). Computer software controlled the delivery of stimuli and the recording of eyelid EMG. One circuit permitted delivery of a shock stimulus $(2.0 \mathrm{~mA}, 60 \mathrm{~Hz}$, constant current, with $8.33 \mathrm{msec}$ current pulses separated by $8.33 \mathrm{msec}$ of no stimulation) via a stimulus isolator (model number 365A, World Precision Instruments, Sarasota, FL). EMG activity recorded by two stainless steel eyelid electrodes was amplified and integrated by equipment similar to that used in our previous studies and designed by Skelton (Skelton, 1988; Stanton et al., 1992; rreeman et al., 1993).

Eyeblink conditioning procedures. The eyeblink conditioning procedures have been described previously (Stanton et al., 1992; Freeman et al., 1993). Three sessions (100 trials/session) were run for each day of training, at approximately 5-6 hr intervals. Before the first session, pups were given about $10 \mathrm{~min}$ of habituation to the test chamber. In the paired condition, training sessions consisted of 10 blocks of 10 trials of delay conditioning. Of these, 9 trials involved pairings of an auditory CS (a $90 \mathrm{~dB}, 2.8 \mathrm{kHz}$ pure tone) and the $2.0 \mathrm{~mA}$ periocular-shock $\mathrm{US}$; and 1 trial was a CS-alone test trial. The CS was $380 \mathrm{msec}$ in duration and coterminated with the $100 \mathrm{msec}$ US, thus yielding an interstimulus interval of $280 \mathrm{msec}$. A pre-CS period of $280 \mathrm{msec}$ was recorded on each trial. Trials were separated by a variable intertrial interval that averaged $30 \mathrm{sec}$ (range $=18-42 \mathrm{sec}$ ). In the unpaired control condition, the CS and US were presented in a pseudorandom order such that no more than three presentations of either stimulus occurred consecutively. The average interval between stimuli was $15 \mathrm{sec}$, and each session contained $100 \mathrm{CS}$ and $100 \mathrm{US}$ presentations. In this way, the paired and unpaired groups received the same number of stimulus presentations at the same average rate across each session. For analysis of response amplitudes, conditioned responses (CRs) were defined as responses that crossed a threshold of 0.4 units (amplified/integrated units as described by SkelIon, 1988) above baseline during the CS period after 80 ms. For analysis of CR percentage, the threshold was 1.0 unit above baseline. The threshold for CR amplitude was lower than that of CR percentage in order to include low-amplitude responses, which provides a more accurate average of response amplitude. Unconditioned responses (URs) were defined as responses that crossed the threshold after unconditioned stimulus (US) presentation.

T-Maze apparatus. The T-maze apparatus has been described in detail in previous reports (Freeman and Stanton, 1991, 1992; Freeman et al., 1994). Briefly, rat pups were trained in Plexiglas T-mazes, scaled to the size of infant rats. The reward for entering the "correct" arm was an infusion of light cream that was delivered into a small cup at the end of each arm of the maze. Between trials, animals were placed in intertrial interval (ITI) compartments, made of clear Plexiglas.

T-Maze delayed alternation procedures. The procedures were similar to those used previously (Freeman and Stanton, 1991, 1992; Freeman et al., 1994). For all subjects, the phases of the procedure were deprivation, maze acclimation, and delayed alternation training.

Deprivation of food, water, maternal, and social contact occurred on
PND25 (the evening after the last eyelid conditioning session), approx imately $16 \mathrm{hr}$ before maze acclimation. Maze acclimation took place on PND26. On the next morning (PND27), pups began delayed alternation training in squads of eight pups, that were counterbalanced as closely as possible for litter, sex, order of testing, and dosing group. Delayed alternation training took place over two sessions, which began $6 \mathrm{hr}$ apart. The first session consisted of two 12 trial blocks, while the second consisted of three 12 trial blocks. Trials consisted of a pair of runs. The first part of the trial was a forced run, in which the animal was presented with one of the maze arms and rewarded for entering it. The second part of the trial was a choice run, in which the animal was presented with a choice of the two arms and rewarded for entering the maze arm that they did not enter on the forced run of that trial. The delay between the forced run and the choice run was the amount of time that it took to place the animal back in the start box (approximately $2.0 \mathrm{sec}$ ). After the second session, pups were placed back into their home cages and given ad lib food and water until they were sacrificed for histological analysis.

Conditioned suppression procedures. Following the last eyeblink conditioning session, a subset of pups were deprived of food and water overnight. Ont the next day al approximately 10 A.M., pups were trained to drink light cream $(0.05-1 \mathrm{ml})$ from a small cup placed on the floor of a cage within the conditioning chamber. Training trials consisted of placing the pups within the cage and giving them an opportunity to drink the light cream. All pups were given repeated 5 min trials until they readily approached the feeding cup on two successive trials. Approximately $6 \mathrm{hr}$ later, pups were placed back in the chamber with the food cup on the floor and presented with $20 \mathrm{CS}$-alone trials with the same ITI as used in Experiment $1(30 \pm 12 \mathrm{sec})$. These sessions were videotaped and later scored by two observers who were blind to the experimental group assignments. Each observer scored the type of behavior displayed by the animal preceding each tone presentation and scored whether that behavior was disrupted or suppressed during the $380 \mathrm{msec}$ CS and for up to two seconds after. The types of behaviors scored included drinking, sniffing while stationary, rearing, grooming and locomotion. The inter-rater correlation was 0.96 .

Histology. On the day after training, pups were sacrificed with a lethal injection of Nembutal and transcardially perfused with $100 \mathrm{ml}$ of physiological saline followed by $300 \mathrm{ml}$ chilled $4.0 \%$ paraformaldehyde in $(0.1 \mathrm{M})$ phosphate buffer. After perfusion, the hrains were removed and postfixed in the same fixative for $24 \mathrm{hr}$ and subsequently transferred to $(0.1 \mathrm{M})$ phosphate-buffered saline until they were embedded in paraffin (Fisher Scientific, Pittsburgh, PA). Paraffin sections were cut at $10 \mu \mathrm{m}$ in the sagittal plane and collected serially in a 1 out of 7 series. This method facilitates histological survey of the entire brain in a limited number of sections. Sections from pups in all experiments were stained with cresyl violet.

Neuroanatomical analysis. A general qualitative survey of the subjects' brains was performed using sagittal sections that were stained for Nissl as described above. Sections were examined for loss of cells and other morphological abnormalities such as volume reduction and disrupted cytoarchitecture.

Since it was expected that the primary effect of postnatal exposure to MAM would be a loss of volume within the cerebellar cortex, quantitative analysis focussed on assessing the loss of area in the cerebellum and its primary efferent and afferent nuclei. Each area measure was taken from a single parasagittal section of the cerebellar vermis. The section plane was determined by matching the morphological characteristics of several extracerebellar structures including the hippocampal formation, the trapezoid body, the inferior olive, the pontine nuclei, the facial nucleus, and the shape of the cerebellar deep nuclei. Sections of the vermis were used rather than sections of the hemisphere because there was less between-animal variability in the morphological characteristics of the cell layers in the vermis due to oblique sectioning through convoluted lobules. This single-section approach was used rather than a serial reconstruction approach in order to maximize the number of animals that could be analyzed and to minimize variability between animals. In addition, it was determined empirically that the magnitude of the effects of MAM on measures of area within the cerebellar system did not differ from the vermis to the hemispheres. A comparison of the area of the cerebellum of MAM-treated rats as a percentage of area of saline-injected rats, in parasagittal sections of the vermis $(n=$ $20)$ and hemisphere $(n=7)$. A $t$ test showed that the magnitude of area reduction in the hemisphere did not differ from that of the vermis. It therefore seems unlikely that reconstructing the entire medial-lateral 
extent of the cerebellum would alter the main conclusions of this analysis. The extent of area lost was determined for the whole cerebellum and its cell layers, the cerebellar deep nuclei, the cerebellar white matter, the inferior olive, the pontinc nuclei, and the red nuclei using a computerized image analysis system (Presage, Advanced Imaging Concepts, Inc., Princeton, NJ). Images of the whole cerebellum were grabbed and digitized with a Dage MTI 81 , high-resolution camera $(1 \mathrm{~K} \times 1 \mathrm{~K})$. A combination of thresholding and filtering functions were used to optimally distinguish between the different layers of the cerebellar cortex and deep nuclei. The different constituent layers of the cerebellum were then separated by Boolean algebraic subtractions. The borders of the inferior olive, red nuclei, and pontine nuclei were drawn using a mouseguided stylus and areas were measured from the outlined region. All areas were calculated and scaled by an empirically determined magnification factor. Image analysis was also used to determine the average thickness of the molecular and granule cell layers and to estimate the density of granule cells in lobules IV, VIII, and HVI. Lobules IV and VIII of the vermis were chosen in order to assess whether there were anterior to posterior differences in the effects of MAM on cell density or cerebellar cortical layer thickness. This possibility was suggested by the finding that lobule VIII normally develops later than lobule IV (Altman, 1969). Moreover, these particular lobules were chosen because their flat-ended morphology is more amenable to measuring cell layer thickness and because they exhibit less convolution. Lobule HVI was examined because it is involved in the acquisition of eyeblink conditioning in adults rabbits (Yeo et al., 1985; Lavond et al., 1987; Lavond and Steinmetz, 1989; Harvey et al., 1993) and might possibly be affected to a greater or lessor extent than the vermis lobules IV and VIII. The density of cells within the molecular layer was determined without the aid of the image analysis system, at $60 \times$ (oil immersion objective), under a light microscope, in an $85 \times 125 \mu \mathrm{m}$ box for lobules IV, VIII, and IIVI.

Design. Littermates were assigned to experimental groups with the restriction that no more than one female and one male from each litter was assigned to a given group. Littermates were given injections of saline or MAM $(20 \mathrm{mg} / \mathrm{kg})$ on PND4 and 7 and then given six 100 trial sessions of paired or unpaired training on PND24-25 (three sessions/day). This yielded a 2 (Saline vs MAM) $\times 2$ (Paired vs Unpaired) factorial design. Subsets of these groups were then trained on T-maze delayed alternation (Saline vs MAM) or tested for conditioned suppression [(Saline vs MAM) $\times($ Paired vs Unpaired)] after eyeblink conditioning.

\section{Results}

\section{Eyeblink conditioning}

CR amplitudes. The results of Experiment 1 are shown in Figure 1 (upper graph) in terms of CR amplitudes across six 100-trial sessions. The saline-treated group given paired training acquired rapidly, reaching asymptotic performance by the fourth session. MAM-treated animals given paired training did not reach levels of conditioning comparable to the saline group after 600 training trials. The performance of the two unpaired control groups was essentially identical, conditioned response amplitudes remaining at low levels across training sessions. These results wcre analyzed statistically by a 2 (saline vs $\mathrm{MAM}$ ) $\times 2$ (paired vs unpaired) $\times 6$ (Sessions) $\times 10$ (10-Trial Blocks) analysis of variance (ANOVA). This analysis revealed a Sessions $\times$ Dosing Condition $\times$ Training Contingency interaction, $F(5,310)=8.53$, $p<0.01$. Post hoc tests (Newman-Keuls) showed that the saline group given paired training had higher amplitude CRs than the MAM group given paired training on sessions 2-6 (all comparisons, $p<0.01$ ) and was significantly superior to its unpaired counterpart (all comparisons, $p<0.01$ ). Nlthough the group given MAM and trained in the paired condition were impaired relative to the saline group, it performed significantly better than its corresponding unpaired group (sessions $2-6, p<0.01$ ). Thus, both dosing groups showed significant conditioning but the saline-injected animals had significantly larger CR amplitudes than the MAM-injected animals. This analysis also revealed a Ses-
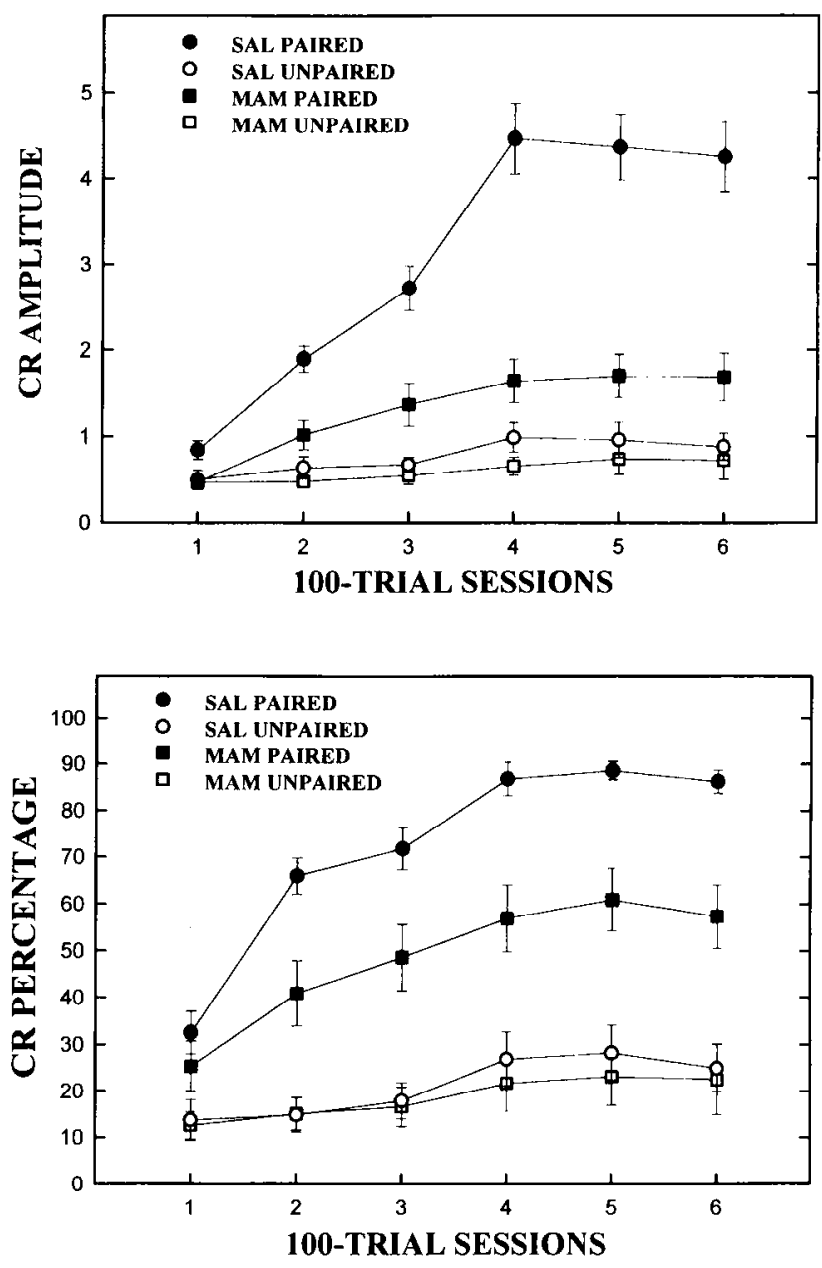

Figure 1. Mean ( $\pm \mathrm{SE}$ ) conditioned response (CR) amplitudes (upper graph) and percentage of CRs (lower graph) for 24-25 d old rat pups injected on PND4 and 7 with saline (circles) or methylazoxymethanol (MAM, squares), as a function of training condition (solid symbols, paired; open symbols, unpaired) and six eyeblink conditioning sessions (100 trials/session; three sessions on PND24 and three on PND25).

sions $\times$ Blocks $\times$ Training Contingency interaction $F(45,2790)$ $=2.01, p<0.01$, which reflected the increased performance of the paired groups across blocks, during the first three sessions. There was also a Blocks $\times$ Dosing Condition interaction $F(9,558)=2.36, p<0.02$. This interaction reflected the rapid increase in performance across blocks, within the first three sessions in the saline group given paired conditioning.

$C R$ percentage. Figure 1 (lower graph) also displays the results of Experiment 1 in terms of percentage CRs across six 100 trial sessions. The pattern of results for the percentage CR measure was similar to that of the $\mathrm{CR}$ amplitude measure. ANOVA revealed a Training Contingency $\times$ Dosing Condition interaction, $F(1,62)=4.21, p<0.05$. Post hoc tests (Newman-Keuls) showed that both dosing groups given paired training were superior to their unpaired controls (both comparisons, $p<0.01$ ) and the saline group showed significantly more CRs than the MAM-treated group $(p<0.01)$. There was also a Sessions $X$ Dosing Group interaction, $F(5,510)=2.45, p<0.04$ and a Sessions $\times$ Blocks $\times$ Contingency interaction, $F(45,2790)=$ $2.47, p<0.001$. The former interaction reflects the rapid increase in performance of the saline group given paired training, 
US-ALONE BLOCK 1

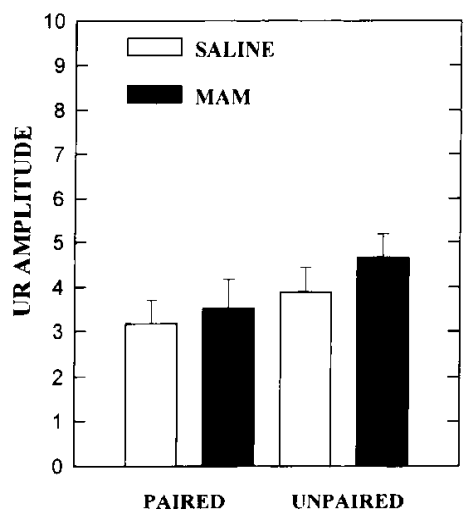

US-ALONE BLOCK 2

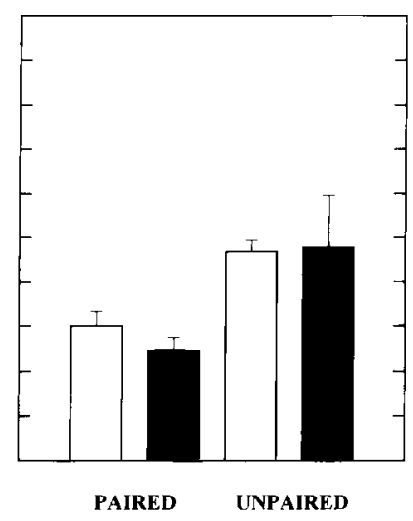

Figure 2. Mean ( $\pm \mathrm{SE}$ ) unconditioned response $(U R)$ amplitudes for $24-25 \mathrm{~d}$ old rats injected with saline (open bars) or MAM (solid bars), as a function of training condition (paired, left; unpaired, right) and blocks of US-alone presentations (block 1, left panel; block 2, right panel). Block 1 occurred prior to Session 1, block 2 after Session 6.

the latter interaction, the increase in performance across blocks, within the first three sessions in both paired groups.

$C R$ latency. The peak latency of CRs was assessed for the tone-alone test trials which were given every tenth trial (see Eyeblink conditioning procedures). MAM did not affect the CR latency [Saline session means and SEMs = (1) $268.2 \pm 19.5$, (2) $291.9 \pm 11.1$, (3) $305.5 \pm 13.0$, (4) $288.1 \pm 9.4$, (5) 292.5 \pm 8.82 , (6) $294.5 \pm 12.6 \mathrm{msec}$; MAM session means and SEMs $=$ (1) $261.1 \pm 9.7$, (2) $293.8 \pm 18.6$, (3) $301.6 \pm 10.1$, (4) $288.6 \pm 10.3$, (5) $299.7 \pm 11.6,(6) 299.8 \pm 12.9 \mathrm{msec}]$. This analysis has not ruled out the possibility that MAM-induced cerebellar hypoplasia could reduce CR latency since only shortdelay conditioning was examined. Further studies could shed more light on this issue by examining the effects of MAM on CR timing using two CSs with different interstimulus intervals. This strategy has been used successfully to illustrate the role of the cerebellar cortex in CR timing (Perrett et al., 1993).

$U R$ amplitudes. The performance of the UR was tested in a subgroup of animals from Experiment 1 (Saline/Paired $n=9$, MAM/Paired $n=9$, Saline/Unpaired $n-4$, MAM/Unpaired $n$ $=4$ ) that were given two 10 trial sessions in which the US was presented alone. One session occurred before the first training session and the other occurred after the last training session. The results of this analysis are shown in Figure 2. Neonatal exposure to MAM had no effect on UR amplitude during US-alone trials. An ANOVA revealed that there was an effect of Contingency, $F(1,22)=7.64, p<0.02$, which reflected stronger unconditioned responding in the unpaired groups, particularly during the second US-alone session. There were no significant effects relating to the variables of dosing condition or blocks.

These results show that MAM impaired associative eyelid conditioning in infant rats without affecting unconditioned responding. The performance of the MAM-treated group given paired conditioning appeared to be more impaired when the CR amplitude measure was used. This could mean that the primary deficit in the MAM-treated animals is in the magnitude of the CR, not in the establishment of CS-US associations. However, it is also possible that the neural plasticity supporting associative conditioning is weaker in the MAM-treated animals.

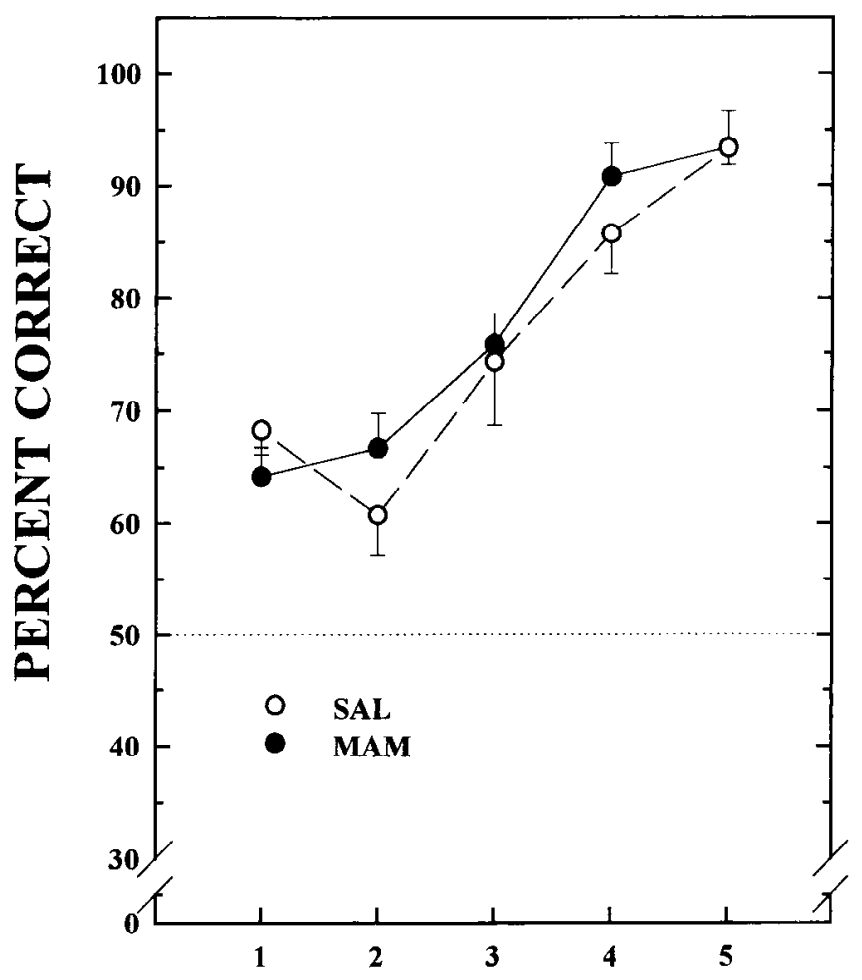

\section{2-TRIAL BLOCKS}

Figure 3. Mean ( $\pm \mathrm{SE}$ ) percentage correct responding on $\mathrm{T}$-maze delayed alternation on PND27 for rat pups injected with saline (open circles) or MAM (solid circles) on PND4 and 7, as a function of 12trial blocks.

\section{T-Maze delayed alternation}

Delayed alternation was completely unaffected by this neonatal MAM treatment (Fig. 3). Pups given MAM (20 mg/kg) on PND4 and 7 (solid circles) learned delayed alternation as well as pups given saline injections (open circles). Both groups showed increased alternation across blocks. ANOVA revealed a main effect of blocks $F(4,76)=30.60, p<0.01$, indicating that both groups improved their performance across blocks. There were no effects relating to dosing conditions. These results suggest that the forebrain circuitry that is critical for delayed alternation was not affected functionally by neonatal exposure to MAM.

\section{Conditioned suppression}

The results of the conditioned suppression test are shown in Figure 4 as the percentage of trials with disrupted behavior in two 10 trial blocks. The animals trained in the paired condition showed strong conditioned suppression when compared to the unpaired control groups. Exposure to MAM did not effect this type of conditioned response. These results were supported by ANOV $\Lambda$ which revealed only a main effect of Training Contingency, $F(1,20)=63.94, p<0.001$. This paradigm demonstrated equivalent levels of retention of a suppressive CR in both dosing groups. This suggests that the MAM-treated pups were able to learn an association between the tone-CS and shock-US. If the conditioned suppression in this paradigm refiected conditioned fear, it is likely that the amygdala and associated circuitry support this CR (Ilitchcock and Davis, 1986; Romanski and LeDoux, 1992; Kim et al., 1993). If so, it may be that the amygdala 


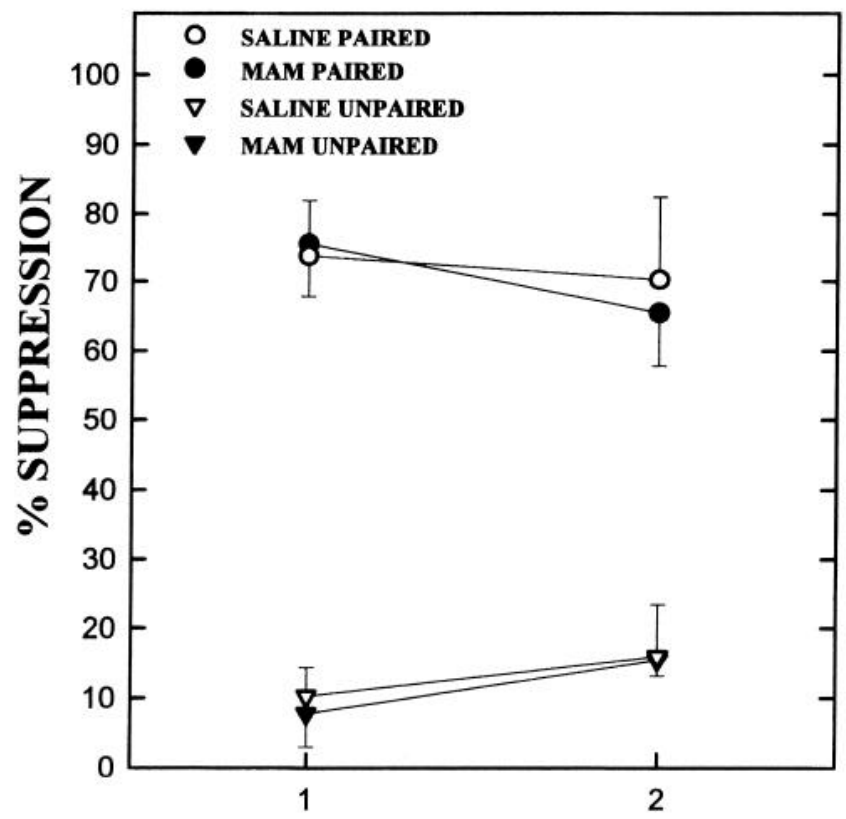

10-TRIAL BLOCKS

Figure 4. Mean $( \pm \mathrm{SE})$ percentage of trials with suppressed behavior on PND26 of rat pups injected with saline (open symbols) or MAM (solid symbols) on PND4 and 7, as a function of the training procedures used during eyeblink conditioning (circles, paired; triangles, unpaired) and 10-trial blocks.

and some of its connections were functionally unaffected by MAM.

\section{Neuroanatomical assessment}

Qualitative neuroanatomy. The primary histological effect of neonatal exposure to MAM seen in animals sacrificed on PND26 was dramatic cerebellar hypoplasia (Fig. $5 B$ ). The volume of the cerebellar cortex and underlying white matter was greatly reduced. In addition to the loss of volume, the cellular organization
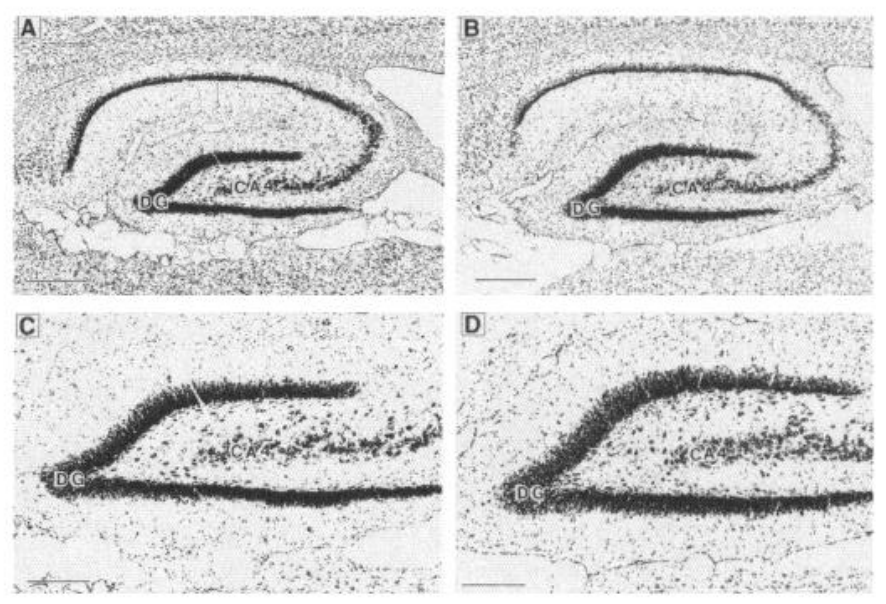

Figure 6. Parasagittal sections of the dorsal hippocampus from $26 \mathrm{~d}$ old pups dosed with saline $(A)$ or MAM $(20 \mathrm{mg} / \mathrm{kg})(B)$ and dentate gyrus (saline, $C$; MAM, $D$ ). Note the lack of dysmorphology in the hippocampus $(C A 4)$ and dentate gyrus $(D G)$ of MAM-treated pups $(B$, $D$ ). Scale bars: $A$ and $B, 500 \mu \mathrm{m} ; C$ and $D, 200 \mu \mathrm{m}$.

of the cerebellar cortex was disrupted. There were ectopic granule cells in the molecular layer of most lobules in the posterior lobe of the cerebellum (Fig. 5D). The incidence of these ectopic cells was highest in lobules VIII-X. Apparently, these cells never descended past the Purkinje cell layer into the granule cell layer. This finding is consistent with studies of the effects of neonatal x-irradiation (Altman and Anderson, 1973) and MAM (Chen and Hillman, 1986). The loss of volume in the granule cell layer also resulted in a disruption of the monocellular pattern of the Purkinje cell layer in the most affected lobules. In less affected lobules, the Purkinje cell layer was monocellular, but the somata were positioned closer together.

Granule cells in another late developing neuroanatomical structure, the hippocampal dentate gyrus, appeared to be unaffected (Fig. 6). The dentate gyrus may have been affected by this MAM treatment at the time of exposure and recovered by
Figure 5. Nissl-stained parasagittal sections from pups sacrificed on PND26 and dosed with MAM on PND4 and 7 $(B, D)$ or saline $(A, C)$. Note the decrease in cerebellar volume in MAMtreated pups $(B)$, and the misalignment of Purkinje cells (indicated by arrows; $D)$. Scale bar: $A$ and $B, 500 \mu \mathrm{m} ; C$ and $D, 100 \mu \mathrm{m}$. $M O L$, Molecular layer; $G R$, granule cell layer.
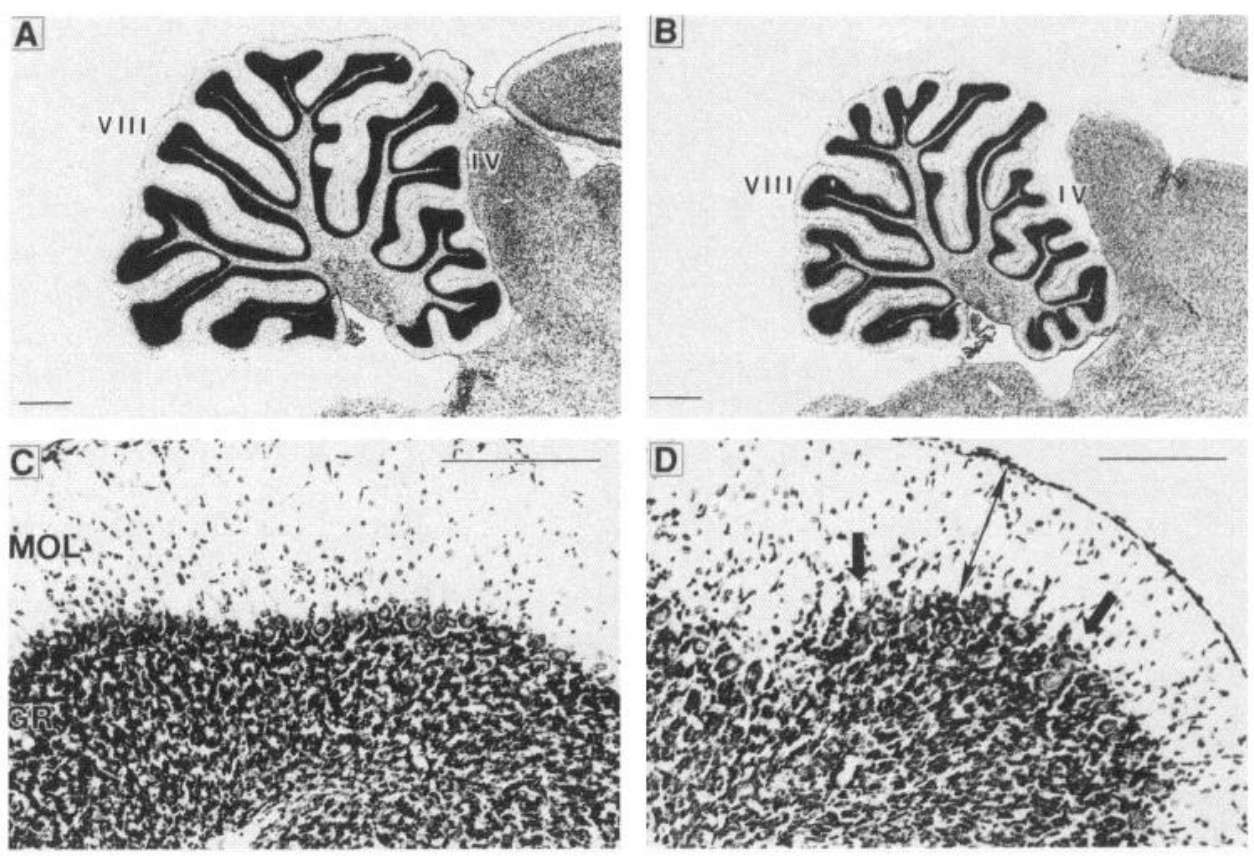

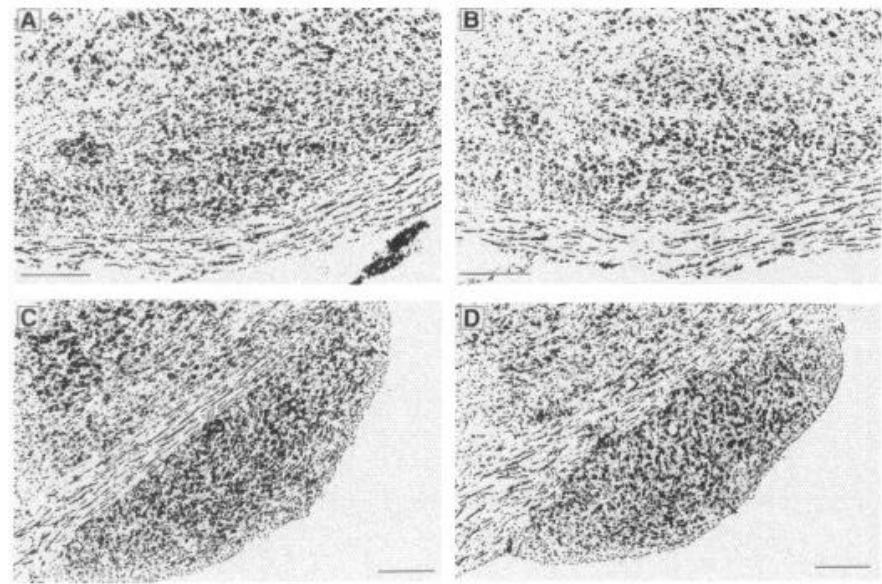

Figure 7. Parasagittal sections of the inferior olive (top row; saline, $A$; MAM, $B$ ) and pontine nuclei (bottom row; saline, $C$; MAM, $D$ ) of animals sacrificed on PND26. Note the normal appearance of the inferior olive and pontine nuclei of MAM-treated animals $(B, D)$. Scale bars, $200 \mu \mathrm{m}$.

the day of assessment. There were no signs of cell loss or other gross abnormalities in the inferior olive or lateral pontine nuclei (Fig. 7), or in the red nuclei or cerebellar deep nuclei (Fig. 8). The cells of the deep nuclei appeared normal, although it was possible that the intercellular space was reduced (Fig. $8 D$; see area analysis below). There were no gross abnormalities in the cochlear nuclei or the trapezoid body (data not shown).

Quantitative neuroanatomy. The parasagittal area of the whole cerebellum and its components were measured in $\mathrm{mm}^{2}$ with an image analysis system (see Quantitative neuroanatomical analysis) and are shown in Figure 9. The area of the whole cerebellum (Fig. 9A), the cerebellar white matter (Fig. 9B), the molecular layer (Fig. 9C) and the granule cell layer (Fig. 9D) were all significantly reduced by approximately $30 \%$ in animals given MAM (solid bars) relative to pups given saline injections (open bars). To compare reductions across regional measures, area in each of these regions was analyzed by a 2 (saline vs MAM) $\times 4$ (whole cerebellum vs molecular layer vs granule cell layer vs white matter) between-within ANOVA, with each area measure transformed as a percentage of the saline controls. This analysis showed that the magnitude of the effect of exposure to MAM did not differ across these measured areas but that there was a main effect of Dose, $F(1,36)=54.60, p<0.0001$. This indicates that all regions measured were reduced in size by exposure to MAM and the magnitude of this effect was the same across regions. Whether there was an effect of Dose on the measured area $\left(\right.$ in $\mathrm{mm}^{2}$ ) of these regions was tested statistically using separate $t$ tests: $t(36)=7.78$, whole cerebellum, $t(36)=4.58$, white matter, $t(36)=6.99$, molecular layer, $t(36)=8.25$, granule cell layer, all $p$ values $<0.001$. Separate $t$ tests were used for this analysis instead of ANOVA because large main effects of area across these measures would obscure the main question of interest.

The thickness of the granule cell layer appeared to be reduced to a lesser degree than the molecular layer in MAM-treated pups although this reduction was not statistically significant (PND26; Table 1). The thickness of the molecular layer was decreased in lobule IV but not lobule VIII in MAM-treated pups (PND26; Table 1). This result was supported by a 2 (saline vs MAM) $\times$ 2 (lobule IV vs lobule VIII) ANOVA of the molecular layer
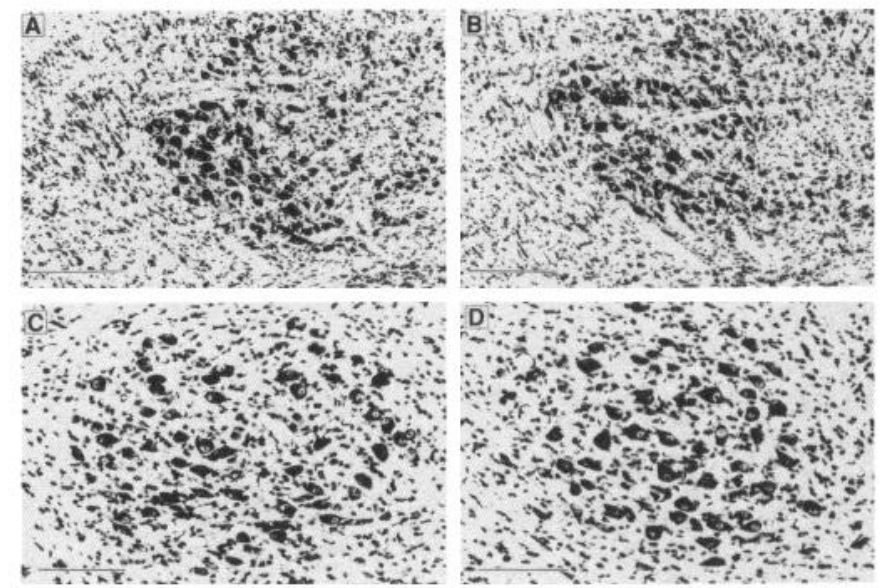

Figure 8. Parasagittal sections of the magnocellular red nucleus (top row; saline, $A$; MAM, $B$ ) and cerebellar deep nuclei (bottom row; saline, $C$; MAM, $D$ ) of animals sacrificed on PND26. Note the normal appearance of the red nuclei and cerebellar deep nuclei of MAM-treated pups $(B, D)$. Scale bars: $A$ and $B, 200 \mu \mathrm{m} ; C$ and $D, 100 \mu \mathrm{m}$.

width, which revealed a Dose $\times$ Lobule interaction, $F(1,12)=$ $6.41, p<0.03$. Post hoc tests (Newman-Keuls) showed that the thickness of the molecular layer of lobule IV was reduced in MAM-treated animals relative to lobule VIII; and to lobule IV of their saline controls (both comparisons, $p<0.05$ ). The relative density of granule cells and cells within the molecular layer were not affected by neonatal exposure to MAM (Table 1). However, the density of ectopic granule cells within the molecular layer was dramatically higher in the MAM-treated animals and was greater in lobule VIII than lobule IV (Table 1). These
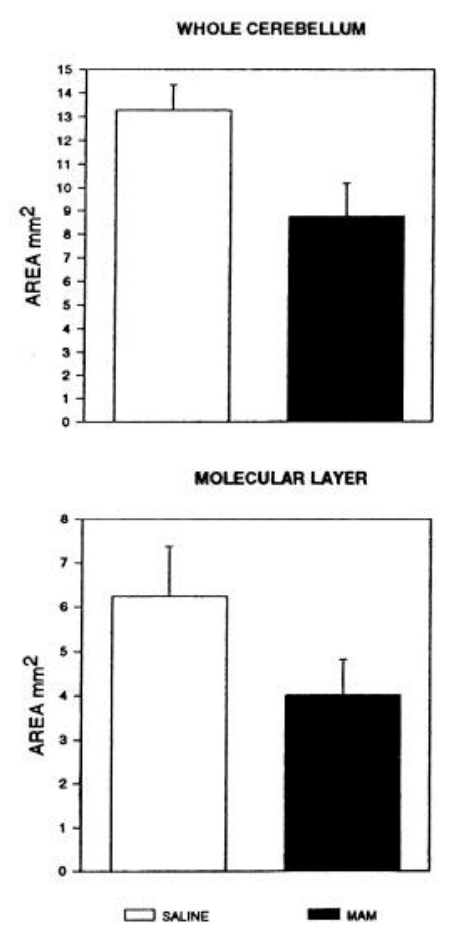

MOLECULAR LAYER

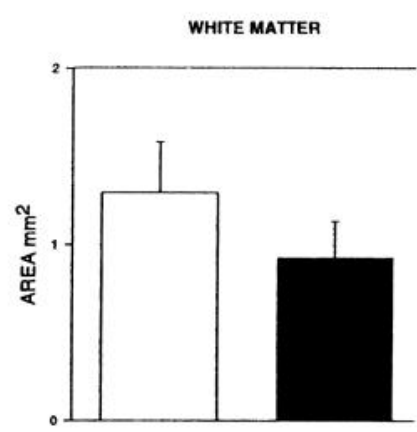

GRANULE CEUL LAYER

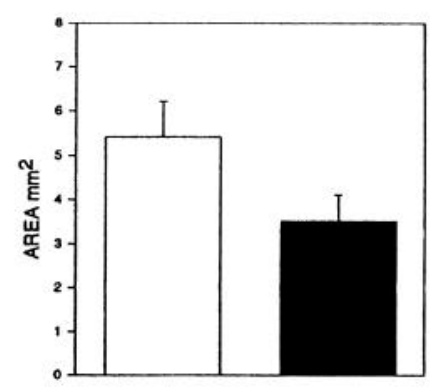

Figure 9. Mean $( \pm \mathrm{SE})$ parasagittal area $\left(\mathrm{mm}^{2}\right)$ of the whole cerebellum (upper left), the cerebellar white matter (upper right), the granule cell layer (lower left), and molecular layer (lower right) of rat pups injected on PND4 and 7 with saline (open bars) or MAM (solid bars) and sacrificed on PND26. 
Table 1. Quantitative analysis of cellular elements of lobules IV, VIII, and HVI from animals sacrificed on PND26

\begin{tabular}{|c|c|c|c|c|c|c|}
\hline & \multicolumn{2}{|c|}{ Lobule IV vermis } & \multicolumn{2}{|c|}{ Lobule VIII vermis } & \multicolumn{2}{|c|}{ Lobule VI hemisphere } \\
\hline & Saline & MAM & Saline & MAM & Saline & MAM \\
\hline $\begin{array}{l}\text { Molecular layer } \\
\text { width }\end{array}$ & $\begin{array}{c}122.51 \mu \mathrm{m} \\
\pm 20.93\end{array}$ & $\begin{array}{l}92.49 \mu \mathrm{m}^{*} \\
\pm 10.17\end{array}$ & $\begin{array}{c}124.75 \mu \mathrm{m} \\
\pm 7.26\end{array}$ & $\begin{array}{c}123.54 \mu \mathrm{m} \\
\pm 27.65\end{array}$ & $\begin{array}{l}103.25 \mu \mathrm{m} \\
\pm 9.51\end{array}$ & $\begin{array}{l}88.18 \mu \mathrm{m} \\
\quad \pm 5.19\end{array}$ \\
\hline $\begin{array}{l}\text { Granule cell layer } \\
\text { width }\end{array}$ & $\begin{array}{c}238.49 \mu \mathrm{m} \\
\pm 36.70\end{array}$ & $\begin{array}{c}196.32 \mu \mathrm{m} \\
\pm 51.22\end{array}$ & $\begin{array}{c}262.10 \mu \mathrm{m} \\
\pm 42.60\end{array}$ & $\begin{array}{c}217.40 \mu \mathrm{m} \\
\quad \pm 42.48\end{array}$ & $\begin{array}{c}166.59 \mu \mathrm{m} \\
\pm 10.41\end{array}$ & $\begin{array}{l}156.49 \mu \mathrm{m} \\
\pm 10.88\end{array}$ \\
\hline $\begin{array}{l}\text { Molecular layer cell } \\
\text { density }\end{array}$ & $\begin{array}{l}2030.25 / \mathrm{mm}^{2} \\
\quad \pm 209.45\end{array}$ & $\begin{array}{c}2299.16 / \mathrm{mm}^{2} \\
\pm 463.82\end{array}$ & $\begin{array}{c}2406.72 / \mathrm{mm}^{2} \\
\quad \pm 265.41\end{array}$ & $\begin{array}{l}2258.82 / \mathrm{mm}^{2} \\
\quad \pm 406.63\end{array}$ & $\begin{array}{c}2984.88 / \mathrm{mm}^{2} \\
\quad \pm 156.03\end{array}$ & $\begin{array}{c}3321.01 / \mathrm{mm}^{2} \\
\quad \pm 181.05\end{array}$ \\
\hline $\begin{array}{l}\text { Granule cell layer } \\
\text { densily }\end{array}$ & $\begin{array}{l}37,650.14 / \mathrm{mm}^{2} \\
\quad \leq 838.52\end{array}$ & $\begin{array}{l}38,056.29 / \mathrm{mm}^{2} \\
\pm 651.00\end{array}$ & $\begin{array}{l}38,708.00 / \mathrm{mm}^{2} \\
\quad \pm 790.79\end{array}$ & $\begin{array}{l}37,877.71 / \mathrm{mm}^{2} \\
\quad \pm 782.03\end{array}$ & $\begin{array}{c}32,000.88 / \mathrm{mm}^{2} \\
\pm 1002.33\end{array}$ & $\begin{array}{c}33,966.13 / \mathrm{mm}^{2} \\
\pm 580.73\end{array}$ \\
\hline $\begin{array}{l}\text { Ectopic granule cell } \\
\text { density }\end{array}$ & $\begin{array}{c}13.45 / \mathrm{mm}^{2} \\
+35.78\end{array}$ & $\begin{array}{l}2030.25 * / \mathrm{mm}^{2} \\
+1391.10\end{array}$ & $\begin{array}{l}0.00 / \mathrm{mm}^{2} \\
\pm 0.00\end{array}$ & $\begin{array}{l}3952.94 * / \mathrm{mm}^{2} \\
\quad \pm 1951.67\end{array}$ & $\begin{array}{l}40.34 / \mathrm{mm}^{2} \\
\pm 27.99\end{array}$ & $\begin{array}{l}1573.11 * / \mathrm{mm}^{2} \\
\quad+577.88\end{array}$ \\
\hline
\end{tabular}

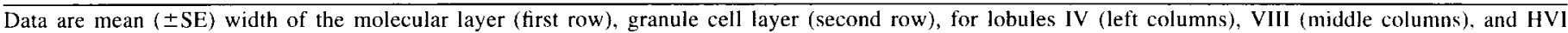

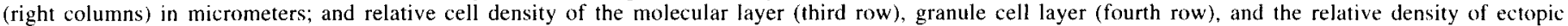
granule cells in the molecular layer (fifth row) per $\mathrm{mm}^{2}$.

* Difference from saline, $p<0.01$.

results were supported by an ANOVA of ectopic granule cell density, which showed a Dose $\times$ Lobule interaction, $F(1,12)=$ 22.20, $p<0.001$. Newman-Keuls tests showed that there were more ectopic granule cells in the molecular layer of both lobule IV and VIII in the group given MAM than their saline controls (both comparisons, $p<0.01$ ) and there were more ectopic granule cells in lobule VIII than lobule IV $(p<0.01)$. The difference in the density of ectopic granule cells in these lobules probably reflects a difference in the proportion of granule cells that were generated following exposure to MAM. Since lobule VIII normally develops later than lobule IV (Altman, 1969), more granule cells were generated in the external germinal layer of lobule VIII after exposure to MAM than lobule IV. Thus, the MAMinduced failure of granule cell migration probably affected more
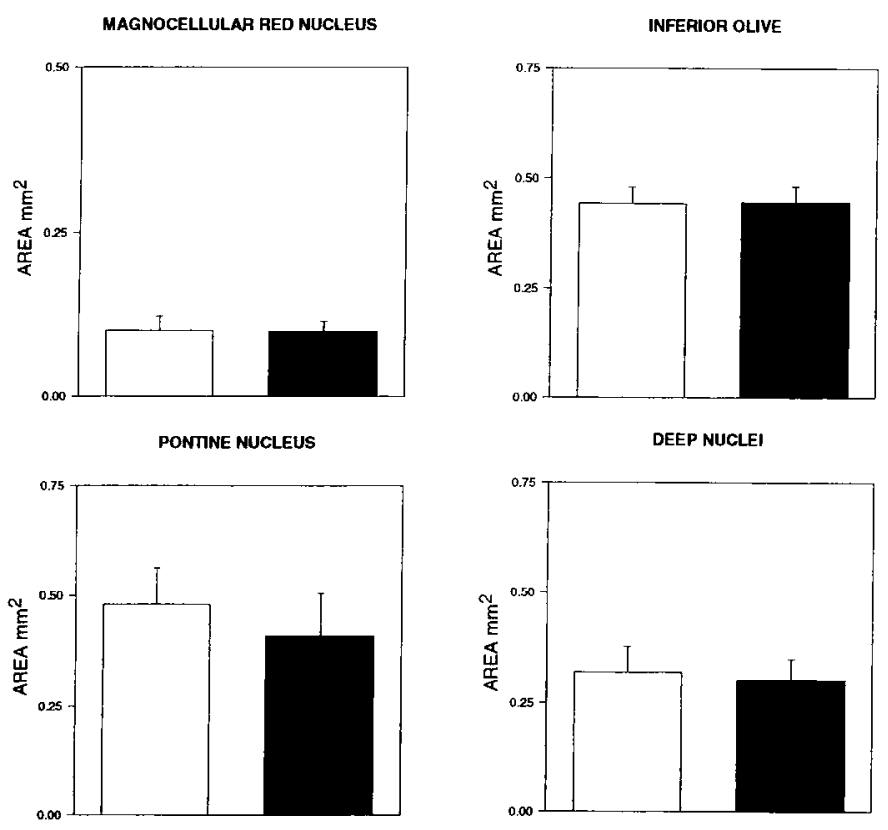

Figure 10. Mean $( \pm \mathrm{SE})$ parasagittal area $\left(\mathrm{mm}^{2}\right)$ of the magnocellular red nucleus (upper left), inferior olive (upper right), pontine nucleus (lower left), and deep nuclei (lower right) of rat pups injected with saline (open bars) or MAM (solid bars) on PND4 and 7, and sacrificed on PND26. cells in lobule VIII than lobule IV. There was no effect of MAM on the width of the molecular or granule cell layers of lobule HVI (Table 1). The relative density of cells in these layers were also unaffected (Table 1). As with lobules IV and VIII, there was a significantly greater density of ectoptic granule cells in lobule HVI of MAM-treated animals, $t(12)=2.65 p<0.03$. An additional analysis compared the magnitude of the effects exposure to MAM on cell layer widths and cell density for lobules IV, VIII and HVI by expressing the data as a percentage of the saline controls. The magnitude of the effect of exposure to MAM was the same for granule cell density, molecular layer cell density, and granule cell layer width across lobules. However, there was a larger reduction in molecular layer width in lobule IV than in lobule VIII or HVI. These results were supported by an ANOVA which examined the width of the molecular layer as a percentage of the saline controls, with lobule as a within-subjects variable. This analysis revealed an effect of Lobule, $F(2,12)=8.87, p<0.005$. Post hoc tests showed that the width of the molecular layer of lobule IV was reduced to a greater degree than lobule VIII or HVI (both comparisons, $p<$ 0.05 ), which did not differ from each other. There was also a significant effect of Lobule for the density of ectopic granule cells, $F(2,12)=19.48, p<0.0003$. Post hoc tests showed that the increase in ectopic granule cell density was greater in lobule VIII than in IV or HVI (both comparisons, $p<0.05$ ).

Overall, these results indicate that although the total volume of the cerebellum is decreased in MAM-treated pups, the thickness and relative density of cells within the molecular and granule cell layers is maintained, with the exception of the reduced molecular layer width in lobule IV. In addition to loss of volume in the cerebellum, the disorganization of cerebellar cortical cytoarchitecture is clearly evident with the presence of ectopic granule cells in the molecular layer. Based upon the extensive connectivity between the cerebellar cortex and the cerebellar deep nuclei, the red nuclei, the pontine nuclei, and the inferior olive, it seemed plausible that these nuclei could also show loss of volume as a secondary consequence of granule cell depletion. The area of these nuclei was measured in parasagittal sections (deep nuclei: saline, $n=18$, MAM, $n=20$; pontine nuclei: saline, $n=7$, MAM, $n=7$; inferior olive: saline, $n=7$, MAM, $n=7$; red nucleus: saline, $n=7$, MAM, $n=7$; Fig. 10). There 


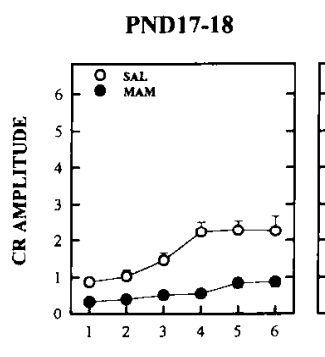

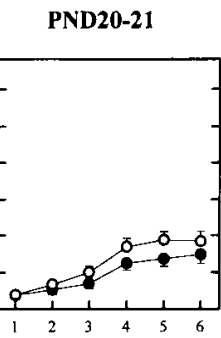

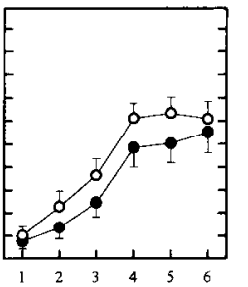

PND24-25

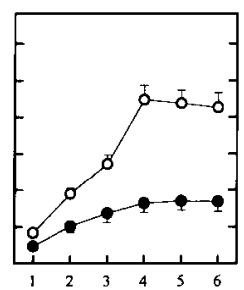

PND31-32
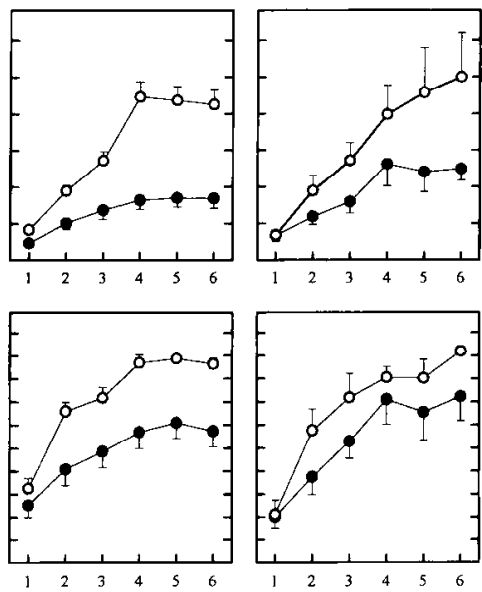

100-TRIAL SESSIONS

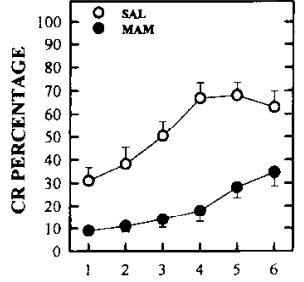

Figure 11. Mean ( $\pm \mathrm{SE})$ conditioned response $(C R)$ amplitudes (upper column) and CR percentage (lower column) for pups injected with saline (open circles) or MAM (solid circles) on PND4 and 7, as a function of age of testing (left panel, PND17-18; middle left panel, $\mathrm{PND} 20-21$; middle right panel, PND24-25; right panel, PND31-32) and six sessions (100 trials/session). was a trend towards a decrease in area of the pontine nuclei but not in any of the other nuclei measured. These observations were clarified by a 2 (saline vs MAM) $\times 4$ (deep nuclei vs pontine nuclei vs inferior olive vs red nucleus) between-within ANOVA and separate $t$ tests, which revealed that there were no significant reductions in the parasagittal area in any of these nuclei. This finding could be viewed as somewhat surprising since loss of volume in the pontine nuclei and the inferior olive is usually associated with lesions of the cerebellum (Castro, 1990), which presumably reflects the loss of synaptic targets.

The qualitative and quantitative neuroanatomical analyses established that the primary effect of neonatal exposure to MAM was on postnatal development of cerebellum and not other postnatally developing structures such as the hippocampal dentate gyrus. This study cannot comment on whether systems associated with the cerebellar cortex are functioning normally in MAM-treated animals. However, it is likely that any functional abnormalities seen in systems outside of the cerebellar cortex are associated with the loss of cerebellar microneurons and the cytoarchitectural disorganization that follows.

In summary, the behavioral and neuroanatomical specificity of the effects of neonatal exposure to MAM suggest that poor acquisition of eyeblink conditioning was primarily a consequence of cerebellar hypoplasia. Experiment 2 was designed to developmentally characterize the effects of MAM on brain maturation and the ontogeny of eyeblink conditioning.

\section{Experiment 2}

Experiment 2 evaluated the effects of early exposure to MAM on age-related increases in rate of eyeblink conditioning. It was possible that MAM-treated animals would show either larger deficits, or recovery from early deficits, as they became more mature. To test these possibilities, pups were given injections of MAM or saline on PND4 and 7 and then tested on eyeblink conditioning across an age range representative of normal ontogeny. The ages chosen have historically corresponded to very immature (PND17-18), intermediate (PND20-21), and mature (PND31-32) levels of conditioning, respectively. This provided a means of examining the effects of early exposure to MAM in subjects that were both less and more mature than those used in Experiment 1 (PND24-25). The neuroanatomical effects of MAM were examined both qualitatively and quantitatively at all ages tested.

\section{Materials and Methods}

Subjects and dosing. Subjects were 64 Long-Evans rat pups (Saline, $n$ $=31$; MAM, $n=33$, from 13 litters). All information regarding the subjects and dosing were identical to those in Experiment 1 except that pups trained on PND17-18 and 20-21 were housed as litters with their dams between eyeblink conditioning sessions.

Eyeblink conditioning procedures. The apparatus and surgical, dosing, and training procedures were identical to those used in Experiment 1 except that the ages of testing were different and there were no unpaired groups in this experiment.

Design. Pups were given subcutaneous injections of saline or MAM $(20 \mathrm{mg} / \mathrm{kg})$ on PND4 and 7 and then given six 100 trial sessions of paired training on PND17-18, PND20-21, or PND31-32 (three sessions/day). This yielded a 2 (saline vs MAM) $\times 3$ (PND17-18 vs PND20-21 vs PND31-32) factorial. The neuroanatomical analysis was similar to that in Experiment 1 except that animals were sacrificed at PND19, 22, and 33 for morphological assessment.

\section{Results}

\section{Behavioral}

CR amplitudes. The results of Experiment 2 are presented in Figure 11 in terms of CR amplitude across six 100-trial sessions. The results from the paired groups in Experiment 1 have been added to this figure to facilitate comparisons across development. These results showed that the effects of MAM on conditioning were present as soon as conditioning emerged and persisted as pups became more mature. Saline-treated animals showed a large developmental increase in conditioning between PND17 and PND33. By comparison with Experiment 1 (Fig. 1), it appears that this increase occurred between PND17 and PND24 and did not increase further by PND33 (Fig. 11). The MAM-treated animals showed a much more modest increase in conditioning with increasing age and did not show levels of conditioning that were comparable to saline-injected animals. These results were supported statistically by ANOVA, which revealed a Sessions $\times$ Age of Testing $\times$ Dosing Condition interaction, $F(10,290)=2.17, p<0.02$. Post hoc tests (NewmanKeuls) demonstrated that the saline-injected animals trained on PND31-32 showed a significant increase in performance between the first and second training session $(p<0.01)$. Pups in this group were superior to their MAM-injected counterparts on sessions 3-6 (all comparisons, $p<0.01$ ) and were superior to the saline-injected animals trained on PND17-18 or PND20-21 during sessions 3-6 (all comparisons, $p<0.01$ ). The MAMtreated animals also improved their performance with increasing 
age. The MAM-treated animals trained on PND31 32 were superior to the MAM-treated animals trained on PND17-18 and those trained on PND20-21 on sessions 2-6 (all comparisons, $p$ $<0.01)$. The saline-injected animals trained on PND17-18 showed higher amplitude CRs than their MAM-treated counterparts on sessions 3-6 (all comparisons, $p<0.01$ ). However, the saline-injected animals trained on PND20-21 did not differ from the MAM-treated animals trained at this age. The rapid increase in conditioning in the saline-injected animals trained on PND3132 was also seen across hlocks, Sessions $\times$ Blocks $\times$ Age of Testing $\times$ Dosing Condition interaction, $F(90,2610)=1.61, p$ $<0.01$. These findings suggest that the effects of neonatal MAM exposure persist and do not allow for functional recovery or represent a transient developmental delay.

$C R$ percentage. The results of the $C R$ percentage analysis are also displayed in Figure 11 . As with the CR amplitude analysis, the MAM-treated animals were impaired at the earliest point in development when conditioning began to emerge in saline-injected pups. However, the effect was considerably weaker when percentage of CRs was measured than when CR amplitudes were measured. ANOVA revealed an Age of Testing $\times$ Dosing Condition interaction, $F(2,58)=3.23, p<0.05$. Post hoc tests (Newman-Keuls) demonstrated that the MAM-injected animals trained on PND17-18 were impaircd when compared to their saline-injected controls $(p<0.01)$, while animals trained on PND20-21 or PND31-32 were unimpaired. This ANOVA also revealed a Sessions $\times$ Blocks $\times$ Age of Testing $\times$ Dosing condition interaction, $F(90,2610)=1.31, p<0.03$. Post hoc tests (Newman-Keuls) of this interaction showed that the MAM-injected animals trained on PND17-18 showed a lower percentage of CRs than their saline-injected counterparts on all blocks (all comparisons, $p<0.05$ ). Pups given MAM that were trained on PND20-21 had fewer CRs than their saline-injected controls only on blocks $42-45$ (all comparisons, $p<0.05$ ). MAM-injected pups trained on PND31-32 were impaired relative to their saline-injected controls on blocks 15-21, 42-46, and 51-60 (all comparisons, $p<0.05$ ). These results show that the primary effect of early exposure to MAM in weanling rats was a deficit in CR amplitudes, with only a mild effect on the frequency of CRs. This pattern of results is similar to that of cerebellar cortical lesions in adult rabbits (Lavond and Steinmetz, 1989). However, when MAM-treated animals are trained on PND1718 there is a large deficit on CR percentage as well as CR amplitude. This could indicate that there are deficits in the cerebellar deep nuclei that recover.

UR amplitudes. As in Experiment 1, analysis of UR amplitudes in Experiment 2 showed no main effects or interactions involving MAM treatment, again indicating that MAM-treated pups showed a deficit in conditioning but not in unconditioned responding (Fig. 12). As with Figure 11, the performance of the paired groups from Experiment 1 are displayed in Figure 12 to facilitate comparisons across development.

\section{Neuroanatomical assessment}

Qualitative neuroanatomy. The results of the analysis of Nisslstained sections were similar to those seen in Experiment 1 . The main difference was that the magnitude of the difference between pups given saline or MAM appeared to increase with age (Fig. 13). The cerebellum of saline-injected pups continued to grow normally, while growth of the cerebellum in MAM-treated was limited.

Quantitative neuroanatomy. The parasagittal area of the
US-ALONE BLOCK 1

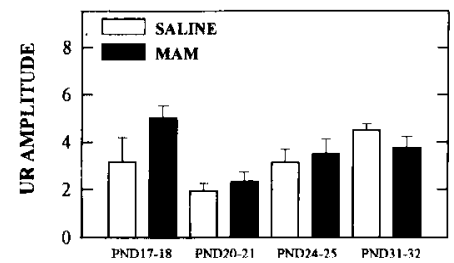

US-ALONE BLOCK 2

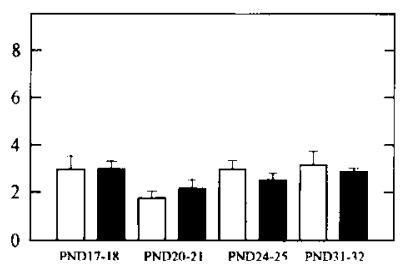

Figure 12. Mean ( $\pm \mathrm{SE})$ unconditioned response (UR) amplitudes for pups injected with saline (open bars) or MAM (solid bars) on PND4 and 7, as a function of age of testing (left to right: PND17-18, PND2021, PND24-25, PND31-32) and blocks of US-alone presentations (block 1, left panel; block 2, right panel). Block 1 occurred prior to Session 1, bock 2 after Session 6.

whole cerebellum and its components were measured at each age of testing (Fig. 14). At all ages, there was a decrease in area of the whole cerebellum (Fig. 14, upper left), the cerebellar white matter (Fig. 14, upper right), the molecular layer (Fig. 14, lower left) and the granule cell layer (Fig. 14, lower right) in MAM-treated pups (solid circles) relative to pups given saline injections (open circles). These results were supported statistically by ANOVAs for each region which all revealed a main effect of Dose: $F(1,55)=218.99$, whole cercbcllum; 76.35 , white matter; 142.31, molecular layer; 150.84, granule cell layer; all $p$ values $<0.001$. There was also a main effect of Age, $F(2,55)=8.39$, for the whole cerebellum; 24.15 for the white matter; 6.30 for the molecular layer (all $p$ values $<0.001$ ), but not for the granule cell layer. In each region, the measured area was reduced by $25-35 \%$ in MAM-treated pups.

The cerebellar deep nuclei showed a minor, but statistically significant reduction in area on PND19 and PND22 (by 14.4 and $14.0 \%$, respectively). This effect was not seen in the animals sacrificed on PND33, which showed a statistically nonsignificant $9.1 \%$ reduction in area. The treatment-related reduction of area in the deep nuclear region was supported statistically by an ANOVA which revealed an effect of Dose, $F(1,55)=9.13, p$ $<0.01$. Separate $t$ tests run at each age showed that the area of deep nuclei region differed between saline and MAM-treated groups on PND19, $t(23)=2.58, p<0.02$ and PND22, $t$ (22) $=3.12, p<0.01$, but not on PND33 (or PND26; see Experiment 1). This result suggests that there is a loss of area in the deep nuclei after exposure to MAM that recovers with maturation. As discussed in Experiment 1, the primary effect of exposure to MAM on PND4 and 7 was cerebellar hypoplasia. None of the ages assessed in this experiment demonstrated gross abnormalities in structures outside of the cerebellum.

In summary, Experiment 2 demonstrated that MAM-induced deficits in conditioning were present as soon as conditioning emerged and persisted as pups became more mature. The MAMtreated animals did show a modest increase in conditioning with increasing age but never showed levels of conditioning that were comparable to saline-injected animals. Thus, the behavioral and neuroanatomical effects of neonatal exposure to MAM were persistent throughout postnatal ontogeny and did not allow functional recovery during this period of development.

\section{Discussion}

This study represents a first step in our attempt to establish the relationship between cerebellar maturation and the ontogeny of eyeblink conditioning in rats. Experiment 1 demonstrated that neonatal exposure to MAM on PND4 and 7 caused severe cer- 
A
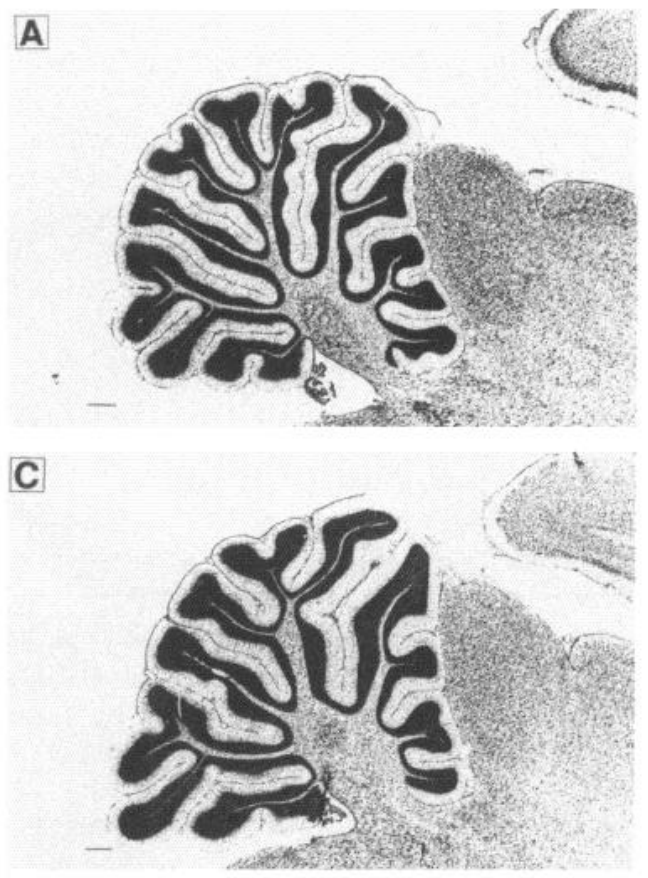

E

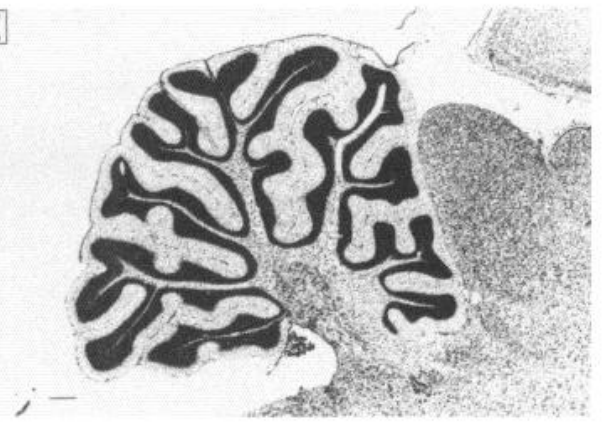

B

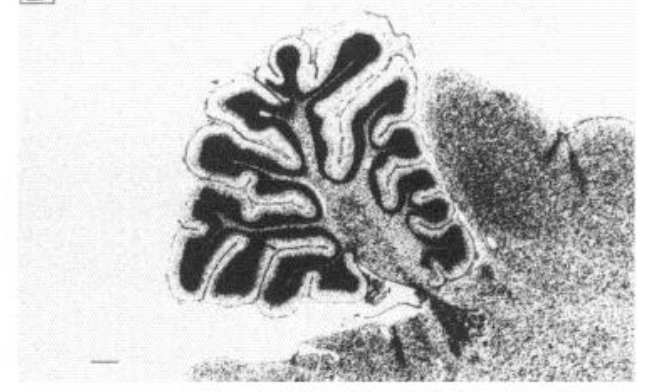

D

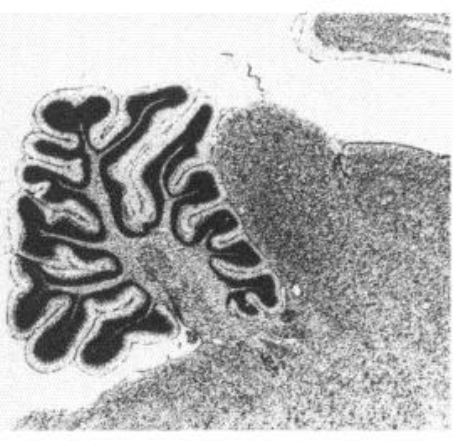

F

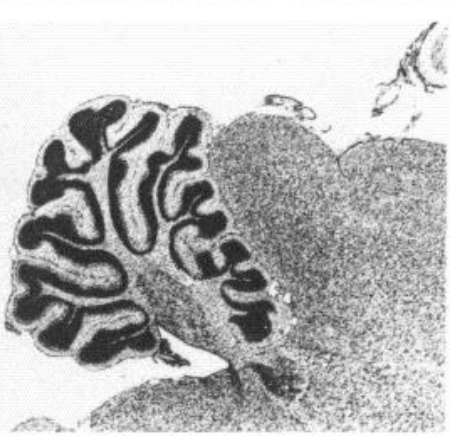

Figure 13. Nissl-stained parasagittal sections from pups dosed with MAM on PND4 and 7 (right column) or saline (left column) and sacrificed on PND19 (top row), PND22 (middle row), and PND33 (bottom row). Note the decrease in cerebellar volume in MAM-treated pups at all ages. Scale bar, $500 \mu \mathrm{m}$. ebellar hypoplasia, with little or no gross dysmorphology in other brain regions. The relative density of granule cells and cells within the molecular layer were not affected by neonatal exposure to MAM. However, the density of ectopic granule cells within the molecular layer was dramatically greater in the MAM-treated animals. These results indicate that although the overall volume of the cerebellum was decreased in MAM-treated pups, the thickness and relative density of cells within the molecular and granule cell layers was relatively stable.

MAM treatment also severely disrupted associative eyeblink conditioning in rats given delay conditioning on PND24-25. However, exposure to MAM had no effect on the unconditioned eyeblink response, T-maze delayed alternation, or conditioned suppression of ongoing behavior. These findings suggest that the brain stem circuits that control the unconditioned eyeblink reflex and the forebrain structures that support spatial delayed alternation and conditioned fear were functionally unaffected by exposure to MAM. On the basis of both behavioral and neuroanatomical measures, the effects of MAM appeared to be primarily confined to the cerebellum. In Experiment 2, the neuroanatomical effects of MAM were similar to those seen in Experiment 1. There was severe cerebellar hypoplasia with no overt dysmorphology in other brain regions. Conditioned response amplitudes were impaired at all ages tested, indicating that there was no functional recovery of this measure of conditioning. However, the effects of MAM were much smaller when CR percentage was measured. Overall, Experiments 1 and 2 clearly demonstrated that normal cerebellar maturation is essential for the ontogenetic increase in CR amplitude.

\section{Neuroanatomical effects of MAM}

In order to interpret the behavioral effects of MAM it is important to consider the primary and secondary neuroanatomical effects of this compound, both outside and within the cerebellum. As indicated previously, the primary effect of neonatal exposure to MAM was cerebellar hypoplasia, and the appearance of ectopic granule cells in the molecular layer. These effects may also have been accompanied by deficits in the development of the dendrites of Purkinje cells and cells of the deep nuclei as a result of the loss of synaptic connections (Altman, 1982). The behavioral effects of MAM may therefore reflect functional impairments in the deep nuclei as well as the cortex.

Cerebellar hypoplasia was probably only partially a consequence of granule cell depletion. Loss of parallel fibers from granule cells that did not divide successfully and poor development of Purkinje cell dendrites probably contributed to the reduction in the area of the molecular layer. Although we did not examine the dendritic morphology of Purkinje cells in this study, studies that have examined the neuroanatomical effects of early $\mathrm{x}$-irradiation with Golgi-stained sections have shown that the development of Purkinje cell dendrites is severely disrupted by neonatal exposure to antimitotics (Altman and Anderson, 

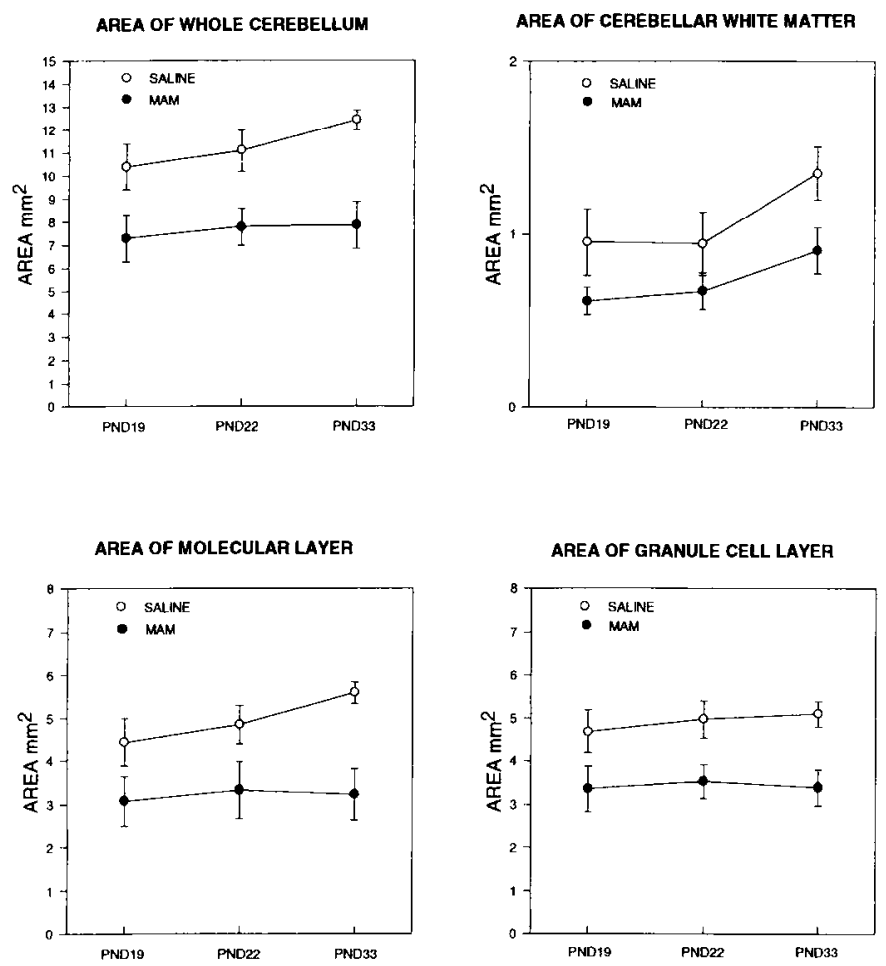

Figure 14. Mean $( \pm \mathrm{SE})$ parasagittal area $\left(\mathrm{mm}^{2}\right)$ of the whole cerebellum (upper left), cerebellar white matter (upper right), molecular layer (lower left), and granule cell layer (lower right), from pups dosed with MAM on PND4 and 7 (solid circles) or saline (open circles) and sacrificed on PND19, 22, and 33.

1973). The volummetric reduction of cerebellar white matter in MAM-treated animals was probably a consequence of the loss of efferent and afferent fibers following the loss of their synaptic targets. This could stem from the inability of cerebellar targets to support new connections from incoming fibers or the degeneration of fibers that had made connections at or around the time of antimitotic treatment. Thus, the loss of cerebellar volume seen following neonatal exposure to MAM probably involved a cascade of developmental disruptions that followed the death of dividing microneurons.

Nevertheless, there was a significant amount of neurogenesis in the cerebellar cortex after exposure to MAM. The cerebellar hypoplasia seen in MAM-injected pups on PND10 was dramatically greater than that seen on PND 19, 22, 26, or 33 (S. Barone, M. E. Stanton, and J. H. Freeman, unpublished observations). This suggests that granule cell progenitors that survived exposure to MAM continued to divide within the external germinal layer and migrate into the developing granule cell layer. Thus, although cerebellar hypoplasia was considerable in MAM-treated animals that were given behavioral training, the cerebellar cortex of these animals generated a large proportion of the remaining granule cells after PND10.

The dentate gyrus appeared to be unaffected by exposure to MAM on PND4 and 7, even though there is considerable mitotic activity in this area during the first postnatal week (Altman and Bayer, 1975). It may be that, relative to the cerebellum, the dentate gyrus is better able to compensate for the loss of mitotic granule cells by generating more cells following exposure to MAM. The hippocampal formation appeared to be functionally normal by PND27, because spatial delayed alternation, a form of learning that fails to develop after early hippocampal damage
(Freeman and Stanton, 1991), was unaffected by exposure to MAM (Fig. 3). In summary, both the behavioral and neuroanatomical analyses in this study suggest that cerebellar hypoplasia was the primary effect of early exposure to MAM and that deficits in conditioning were most likely a consequence of this maturational insult. To more fully address this issue, it is important to consider the relation of the data in this study to what is known about the neural bases of eyeblink conditioning in adult animals.

\section{Comparison of the neural bases of eyeblink conditioning in infants and adults}

This study and a previous one that examined the effects of early cerebellar lesions on eyeblink conditioning in infant rats (Freeman et al., in press) revealed similarities with the functional consequences of cerebellar damage in adult animals (McCormick et al., 1982; Clark et al., 1984; McCormick and Thompson, 1984; McCormick et al., 1984; Lavond et al., 1985; Yeo et al., 1985; Steinmetz et al., 1992). In the developing rat, as in adult rabbits, damage to the cerebellar cortex slows acquisition and impairs CR amplitude, whereas damage to the deep nuclei abolishes conditioning (Freeman et al., in press). The finding that cerebellar hypoplasia did not impair the UR is also consistent with the effects of cerebellar damage in adult rabbits (Steinmetz et al., 1992). Such studies have also shown that the cerebellar hemisphere that is ipsilateral to the conditioned eye constitutes the essential circuitry for eyeblink conditioning (see Thompson, 1988). Early lesions of the ipsilateral cerebellar hemisphere also impair conditioning in infant rats (Freeman et al., in press). These parallels between studies of infants and adults encourage further applications of this preparation to the ontogeny of learning and lend support to the central claim of this study that maturation of the cerebellum is critical for the normal development of eyeblink conditioning.

\section{Eyeblink conditioning as a model system for studying the ontogeny of learning and its neural bases}

We have thus far relied on lesion methods to gather evidence concerning the relationship between maturation of the cerebellum and the development of eyeblink conditioning. Different methods have been used experimentally for this purpose, including aspiration lesions (Freeman et al., in press) and early exposure to MAM (the present study). In both cases, early cerebellar cortical damage has produced a partial impairment of conditioning. However, the performance of $24 \mathrm{~d}$ old rats given MAM on PND4 and 7 was more severely affected than that of pups given lesions of the hemispheric cerebellar cortex alone (Freeman et al., in press). Thus, although it is clcar that MAM produced partial cerebellar cortical hypoplasia, its effects were more severe than lesions of the entire hemispheric cortex. This suggests that either there is some redundancy in the cerebellar cortex such that other areas can help support conditioning after focal lesions or the effects of MAM were more extensive within other aspects of cerebellar circuitry. For example, cerebellar output through the deep nuclei could be weaker following exposure to MAM because the cells of the deep nuclei did not develop fully without normal cortical innervation. Another possibility is that the partial loss of innervation of the deep nuclei caused an abnormal tonic interaction that produced more severe effects than complete ablation. This type of effect has been demonstrated by the finding that disrupting hippocampal activity by lesions of the septum is more detrimental to eyeblink conditioning than total ablation of the hippocampus and overlying cortex (Solo- 
mon et al., 1983). Howcver, it is clcar that this MAM treatment did not produce deficits that were as severe as those following lesions of the cortex plus the underlying deep nuclei (Freeman et al., in press). Thus, early exposure to MAM may produce more widespread functional deficits than lesions of the cerebellar cortex alone, but its effects are not equivalent to hemicerebellectomy.

These observations have important implications for identifying the aspects of neural maturation that are critical for the ontogeny of eyeblink conditioning. Indeed, the performance of weanling rats given MAM on PND4 and 7 (see performance at PND24-25; Experiment 1 and PND31-32; Experiment 2) was more similar to the performance of saline-injected preweanling rats (see performance at PND17-18 and PND20-21; Experiment 2) than that of weanling rats given cerebellar cortical lesions (Freeman et al., in press). Moreover, both MAM-treated animals trained on PND24-25 (Experiment 1) and saline-injected preweanling rats (Experiment 2) showed stronger performance when CR percentage was measured than when CR amplitude was measured. Since the behavioral effects of MAM appear to mimic the performance of preweanling rats better than lesions do, it may be that the ontogeny of eyeblink conditioning depends upon simultaneous developmental changes in multiple elements of cerebellar circuitry. However, specifying these elements and whether they involve intrinsic cerebellar circuitry await further study with additional methodological approaches.

\section{References}

Altman J (1969) Autoradiographic and histological studies of postnatal neurngenesis. III. Dating the time of production and onset of differentiation of cerebellar microneurons in rats. J Comp Neurol 136:269294.

Altman J (1972a) Postnatal development of the cerebellar cortex in the rat. I. The external germinal layer and the transitional molecular layer. J Comp Neurol 145:353-398.

Altman J (1972b) Postnatal development of the cerebellar cortex in the rat. II. Phases in the maturation of Purkinje cells and of the molecular layer. J Comp Neurol 145:399-464.

Altman J (1972c) Postnatal development of the cerebellar cortex in the rat. III. Maturation of the components of the granular layer. J Comp Neurol 145:465-514.

Altman J (1982) Morphological development of the rat cerebellum and some of its mechanisms. In: The cerebellum: new vistas (Palay SL, Chan-Palay V, eds), pp 8-49. Berlin: Springer.

Altman J, Anderson WJ (1972) Experimental reorganization of the cerebellar cortex. I. Morphological effects of elimination of all $\mathrm{mi}-$ croneurons with prolonged $x$-irradiation started at birth. $\mathrm{J}$ Comp Neurol 146:355-406.

Altman J, Anderson WJ (1973) Experimental reorganization of the cerebellar cortex. II. Effects of elimination of most microneurons with prolonged $\mathrm{x}$-irradiation started at four days. J Comp Neurol 149: 123-152.

Altman J, Bayer S (1975) Postnatal development of the hippocampal dentate gyrus under normal and experimental conditions. In: The hippocampus: structure and development, Vol 1 (Isaacson RI, Pribram KH, eds), pp 95-122. New York: Plenum.

Anderson WA, Flumerfelt BA (1985) Purkinje cell growth beyond the twenty-third postnatal day. Dev Brain Res 17:195-200.

Berry M, Bradley P (1976) The growth of dendritic trees of Purkinje cells in the cerebellum of the rat. Brain Res 112:1-35.

Castro AJ (1990) Plasticity in the motor system. In: The cerebral cortex of the rat (Kolb B, Tees RC, eds), pp 563-588. Cambridge, MA: MIT Press.

Chapman PF, Steinmetz JE, Sears LL, Thompson RF (1990) Effects of lidocaine injection in the interpositus nucleus and red nucleus on conditioned behavioral and neuronal responses. Brain Res 537:149156

Chen S, Hillman DE (1986) Selective ablation of neurons by methyl- azoxymethanol during pre- and postnatal brain development. Exp Neurol 94:103-119.

Chen S, Hillman DE (1989) Regulation of granule cell number by a predetermined number of Purkinje cells in development. Dev Brain Res 45:137-147.

Clark GA, McCormick DA, Lavond DG, Thompson RF (1984) Effects of lesions of cerebellar nuclei on conditioned behavioral and hippocampal neuronal responses. Brain Res 291:125-136.

Clark RE, Zhang AA, Lavond DG (1992) Reversible lesions of the cerebellar interpositus nucleus during acquisition and retention of a classically conditioned behavior. Behav Neurosci 106:879-888.

Freeman JH, Stanton ME (1991) Fimbria-fornix transections disrupt the ontogeny of delayed alternation but not position discrimination in the rat. Behav Neurosci 105:386-395

Freeman JH Jr, Stanton ME (1992) Medial prefrontal cortex lesions and spatial delayed alternation in the developing rat: recovery or sparing? Behav Neurosci 106:924-932.

Freeman JH Jr, Spencer CO, Skelton RW, Stanton ME (1993) Ontogeny of eyeblink conditioning in the rat: effects of US intensity and interstimulus interval on delay conditioning. Psychobiology 21:233242.

Freeman JH Jr, Barone S Jr, Stanton ME (1994) Cognitive and neuroanatomical effects of triethyltin in developing rats: role of age of exposure. Brain Res 634:85-95.

Freeman JH Jr, Carter CS, Stanton ME (in press) Early cerebellar lesions impair eyeblink conditioning in developing rats: differential effects of unilateral lesions on postnatal day 10 or 20 . Behav Neurosci, in press.

Gilbert ME, Cain DP (1980) Electrode implantation in infant rats for kindling and chronic brain recording. Behav Brain Res 1:553-555.

Harvey JA, Welsh JP, Yeo CH, Romano AG (1993) Recoverable and nonrecoverable deficits in conditioned responses after cerebellar cortical lesions. J Neurosci 13:1624-1635.

Hitchcock J, Davis M (1986) Lesions of the amygdala, but not of the cerebellum or red nucleus, block conditioned fear as measured with the potentiated startle paradigm. Behav Neurosci 100:11-22.

Kim JJ, Rison RA, Fanselow MS (1993) Effects of amygdala, hippocampus, and periaqueductal gray lesions on short- and long-term contextual fear. Behav Neurosci 107:1093-1098.

Krupa DJ, Thompson JK, Thompson RF (1993) Localization of a memory trace in the mammalian brain. Science 260:989-991.

Lavond DG, Steinmetz JE (1989) Acquisition of classical conditioning without cerebellar cortex. Behav Brain Res 33:113-164.

Lavond DG, Hembree TL, Thompson RF (1985) Effect of kainic acid lesions of the cerebellar interpositus nucleus on eyelid conditioning in the rabbit. Brain Res 326:179-182.

Lavond DG, Steinmetz JE, Yokaitis MH, Thompson RF (1987) Reacquisition of classical conditioning after removal of cerebellar cortex. Exp Brain Res 67:569-593.

McCormick DA, Clark GA, Lavond DG, Thompson RF (1982) Initial localization of the memory trace for a basic form of learning. Proc Natl Acad Sci 79:2731-2735.

McCormick DA, Thompson RF (1984) Cerebellum: essential involvement in the classically conditioned eyelid response. Science 223:296299.

Perrett SP, Ruiz BP, Mauk MD (1993) Cerebellar cortex lesions disrupt learning-dependent timing of conditioned eyelid responses. J Neurosci 13:1708-1718.

Romanski LM, LeDoux JE (1992) Equipotentiality of thalamo-amygdala and thalamo-cortico-amygdala circuits in auditory fear conditioning. J Neurosci 12:4501-4509.

Skelton RW (1988) Bilateral cerehellar lesions disrupt conditioned eyelid responses in unrestrained rats. Behav Neurosci 102:586-590.

Solomon PR, Solomon SD, Vander Schaaf E, Perry HE (1983) Altered activity in the hippocampus is more detrimental to classical conditioning than removing the structure. Science 220:329-331.

Stanton ME, Freeman JH Jr (1994) Eyeblink conditioning in the infant rat: an animal model of learning in developmental neurotoxicology. Env Health Perspect 102:131-139.

Stanton ME, Freeman JH Jr, Skelton RW (1992) Eyeblink conditioning in the developing rat. Behav Neurosci 106:657-665.

Steinmetz JE, Lavond DG, Ivkovich D, Logan CG, Thompson RF (1992) Disruption of classical eyelid conditioning after cerebellar lesions: damage to a memory trace system or simple performance deficit? J Neurosci 12:4403-4426. 
Thompson RF (1988) The neural basis of basic associative learning of discrete behavioral responses. Trends Neurosci 11:152-155.

Thompson RF, Donegan NH, Clark GA, Lavond DG, Lincoln JS, Madden J IV, Mamounas LA, Mauk MD, McCormick DA (1987) Neuronal substrates of discrete, defensive, conditioned reflexes, conditioned fear states, and their interactions in the rabbit. In: Classical conditioning, 3rd ed (Gormezano I, Prokasy WF, Thompson RF, eds), pp 371-399. Hillsdale, NJ: Erlbaum.

Weisz DJ, LoTurco JJ (1988) Reflex facilitation of the nictitating membrane response remains after cerebellar lesions. Behav Neurosci 102: 203-209.

Wcisz DJ, Harden DG, Xiang Z (1992) Effects of amygdala lesions on reflex facilitation and conditioned response acquisition during nictitating membrane response conditioning in rabbit. Behav Neurosci 106:262-273.

Welsh JP, Harvey JA (1989) Cerebellar lesions and the nictitating membrane reflex: performance deficits of the conditioned and unconditioned response. J Neurosci 9:299-311.

Yeo $\mathrm{CH}$, Hardiman MJ, Glickstein M (1985) Classical conditioning of the nictitating membrane response of the rabbit. I. Lesions of the cerebellar nuclei. Exp Brain Res 60:87-98.

Yeo CH, Hardiman MJ, Glickstein M (1985) Classical conditioning of the nictitating membrane response of the rabbit. II. Lesions of the cerebellar cortex. Exp Brain Res 60:99-113. 